\title{
Femoroacetabular Impingement: What the Surgeon Wants to Know
}

\author{
Paulo Rego, MD, PhD ${ }^{1}$ Paul E. Beaulé, MD, PhD 2 Olufemi R. Ayeni, MD, PhD 3 Marc Tey, MD \\ Oliver Marin-Peña, $\mathrm{MD}^{5}$ Pedro Dantas, $\mathrm{MD}^{6}$ Geoffrey Wilkin, $\mathrm{MD}^{2}$ George Grammatopoulos, MD ${ }^{2}$ \\ Inês Mafra, MD ${ }^{7}$ Kevin Smit, MD ${ }^{8}$ Adrian Z. Kurz, MD ${ }^{3}$
}

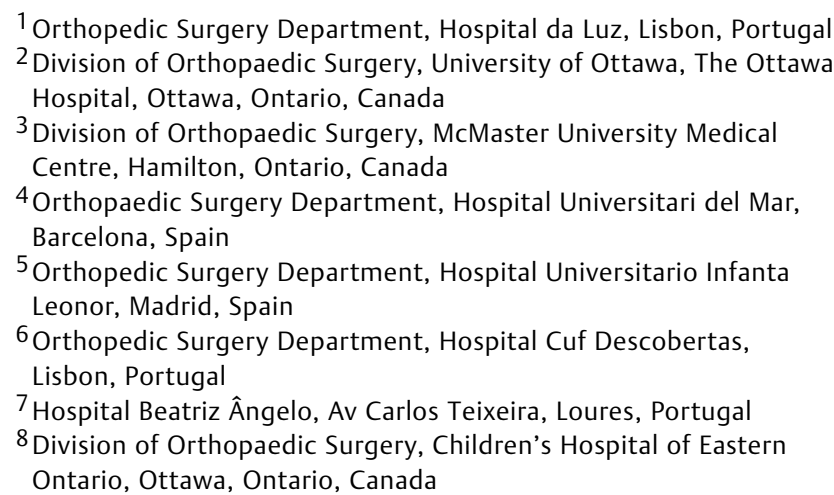

Address for correspondence Paulo Rego, MD, PhD, Department of Orthopaedic Surgery, Hospital da Luz, Avenida Lusíada, 100, 1500-650 Lisbon, Portugal (e-mail: pauloamaralrego@gmail.com).

Semin Musculoskelet Radiol 2019;23:257-275.

\begin{abstract}
Keywords

- femoroacetabular impingement

- hip arthroscopy

- hip dysplasia

- acetabular retroversion

- periacetabular osteotomy

Femoroacetabular impingement (FAI) is increasingly recognized as a risk factor for early hip degeneration in young active patients. The diagnosis depends on clinical examination and proper imaging that should be able to identify abnormal and sometimes subtle morphological changes. Labral tears and cartilage lesions rarely occur without underlying bone abnormalities. Surgical approaches to treat FAI are increasing significantly worldwide, even without a clearly defined consensus of what should be accepted as the standard imaging diagnosis for FAI morphology.

Hip abnormalities encompass many variations related to the shape, size, and spatial orientation of both sides of the joint and can be difficult to characterize if adequate imaging is not available.

This article presents a comprehensive review about the information orthopaedic surgeons need to know from radiologists to plan the most rational approach to a painful hip resulting from a mechanical abnormality.
\end{abstract}

Since Smith-Petersen described femoroacetabular impingement (FAI) for the first time in $1936,{ }^{1}$ the concept has evolved over the years. In the original article, the impact mechanism of the femoral neck against the acetabular rim was already recognized as an important source of pain and disability. It was not until the work developed by Ganz, 2,3 from their direct observation of impinging hips, ${ }^{4}$ that the mechanism of articular damage was fully understood., 5 Three distinct types of intra-articular hip impingement were then described. ${ }^{7}$ The pincer type is characterized by a repetitive impact of the neck against the acetabular rim causing primary labral damage $e^{6,8}$ with progressive loss of its sealing effect. The cam type results from a deformity that alters the normal waist contour of the head-neck junction leading to an intrusion mechanism that increases the contact pressure between the articular surfaces with risk of causing early joint degeneration. In the mixed form, cam and pincer mechanisms are present in the same hip, and the
Issue Theme Hip and Advanced Musculoskeletal Imaging; Guest Editors, Vasco V. Mascarenhas, MD, MBA and Alberto Vieira, MD
Copyright (C) 2019 by Thieme Medical Publishers, Inc., 333 Seventh Avenue, New York, NY 10001, USA. Tel: +1(212) 584-4662.
DOI https://doi.org/ 10.1055/s-0039-1683967. ISSN 1089-7860. 
predominant mechanism depends on the direction of movement. $^{9}$

In the late 1990s, the surgical dislocation technique developed by Ganz direct inspection of these mechanisms of cartilage and labral damage and was considered the keystone for understanding one of the most common mechanical risk factors of early hip osteoarthritis., ${ }^{3,10,11}$ Open or arthroscopic trimming of the acetabular margin with labral refixation and head-neck waist restoration has been established as the standard treatment of FAI syndrome. The concept of hip-preserving surgery evolved over the years including more sophisticated techniques of intra- and extraarticular alignment of the hip based on knowledge of the vascular supply to the proximal femur. Those procedures can be performed on the femoral side, on the acetabular side, or on both sides of the joint. ${ }^{12-14}$

Surgical preservation of an anatomical structure makes more sense than its replacement. In the hip joint, this concept is even more relevant due to the unsolved problems related to the implants used in replacement. However, hip preservation is demanding due to the intra-articular epiphyseal circulation of the femur, the proximity of large neurovascular structures and complexity of anatomical variants of femur torsion, and acetabular socket spatial orientation. For example, in cam impingement, the surgical treatment goal of restoring head sphericity can be difficult to accomplish considering the frequent overlap of cam deformity with the area of perforation of the superior retinacular arteries. ${ }^{15-18}$

In the last decade, the number of performed hip arthroscopies has increased dramatically, much more than osteotomies or other hip-preserving procedures. Some studies point to an increase of 250 to $365 \%$ in the last 10 years. ${ }^{19-21}$ This massive increase should raise some concern about indications, patient selection, and proper understanding of the impingement mechanism before deciding on surgical treatment of a painful hip. We believe hip arthroscopy is becoming very popular due to the fast recovery and return to sports activities but also because it is very attractive to opt for surgery in the presence of an "image-based" diagnosis of an isolated labral tear. Unfortunately, those reported intraarticular lesions rely many times on poor quality imaging where the underlying abnormal bone morphology frequently goes unrecognized. Those two factors can contribute to a poor understanding of the real cause of hip pain, an inappropriate indication for surgery, or even an inadequate surgical approach.

Few studies report more than a 5- to 10-year follow-up after FAI surgery. ${ }^{22,23}$ Thus we do not know for sure if hippreserving procedures will be cost effective and beneficial in the long term. We believe adequate patient selection, proper diagnosis based on good quality imaging, and appropriate surgery are the key factors to achieve good results in hip preservation.

In this article we present the most relevant information that orthopaedic surgeons need from radiologists to make the correct interpretation and appropriate therapeutic decision in a painful hip.

\section{FAI Treatment: An Update}

\section{Indications and Type of Surgery}

In recent years there has been much ongoing discussion about the best FAI treatment approach. Some surgeons argue that hip arthroscopy is the preferred technique in the second decade of the 21 st century. Others believe a direct inspection of the hip joint in motion using the surgical dislocation technique is the best way to understand the cause of hip pain or mechanical symptoms. Personal experience and learning curve possibly can explain individual surgeon preferences. We agree that hip arthroscopy is a powerful technique that has many advantages over open surgery, but the direct observation of intra-articular and extra-articular impingement mechanisms is not possible in the same way.

A recent meta-analysis ${ }^{21}$ showed that indications for arthroscopic surgery vary widely and show a lack of consensus. Some authors based the surgical indication on imaging only and others on clinical findings. Only $56 \%$ of the analyzed studies used a combination of symptoms, clinical signs, and imaging for the diagnosis of FAI. New studies about open surgery to treat FAI have been less frequently reported. The specific indications for open surgical dislocation are revision procedures where the cause of impingement was initially missed; hip impingement where additional extra-articular procedures must be added (relative neck lengthening, proximal femur osteotomies, or acetabular reorientation procedures) ${ }^{24}$; cases of protrusio and secondary acetabular overcoverage due to circumferential labral ossification ${ }^{25}$; and cases where a massive labrum allograft is needed. ${ }^{26}$ With recent detailed knowledge of the vascular supply to the femoral head, resection of lateral cam deformities overlapping the vascular area is no longer an absolute isolated indication for open surgery. ${ }^{17,18}$

The literature is very scarce concerning recommendations for the amount and shape of resection at the head-neck junction and acetabular margin. Few publications define the amount of safe bone resection on the femoral side before creating an increased risk of stress fracture, and there is no consensus about the depth and extension of resection. Kraeutler et $\mathrm{al}^{9}$ clarified the importance of the femoral torsional profile in FAI pathomorphology. According to their study, cam deformity limits flexion while retrotorsion of the neck limits internal rotation. They also point out that probably some patients with this type of morphology would benefit from additional derotational osteotomy added to the usual head-neck junction trimming. The occurrence of this combined morphology could also explain why some hips present a cortical bone reaction inferior (around 4 o'clock) to the distal part of a cam deformity ( - Fig.1), a consequence of neck impingement only in internal rotation at higher degrees of flexion. ${ }^{27}$

This morphology was related previously to $\mathrm{cam}^{27}$ and pincer impingement ${ }^{28}$ with no mention of the hypothetical concept of mixed impingement where the predominant mechanism depends on the direction of movement and the pincer component is mostly due to retrotorsion of the femoral neck. The clinical relevance of these findings is the possibility of performing excessive cam trimming and acetabular anterior 


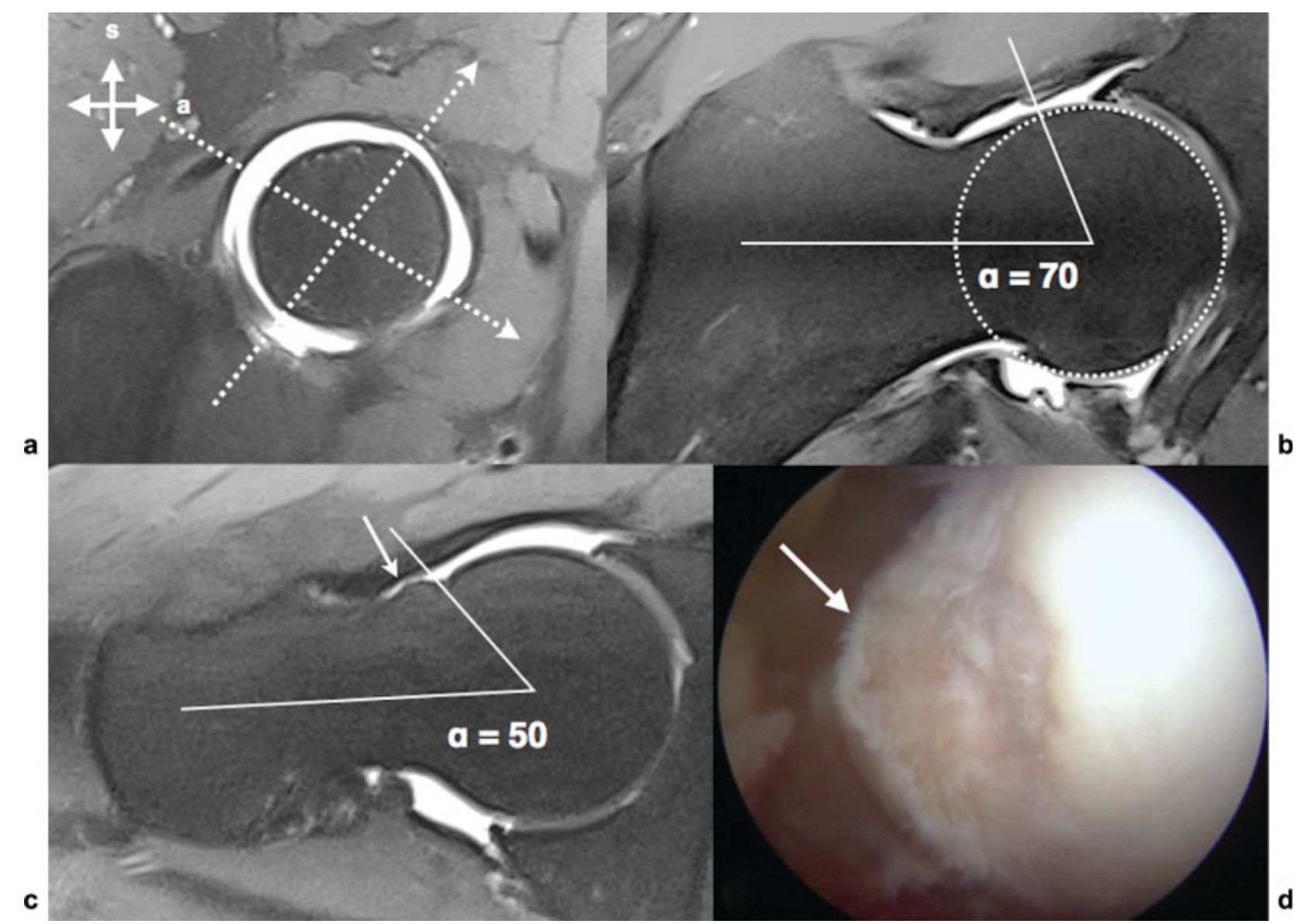

Fig. 1 (a) Magnetic resonance radial plane perpendicular to the femoral neck axis marking the position of two radial planes. (b) Planes at 2 o'clock position showing a cam deformity with an $\alpha$ angle of 70 degrees. (c) Radial plane at 4 o'clock position where we can depict a cortical reaction with bone apposition (arrow) resulting from neck impingement against the acetabular rim and where the $\alpha$ angle is 50 degrees.

(d) intraoperative arthroscopic image of the same patient showing the bone apposition in the head-neck junction. a, anterior; s, superior.

wall resection while addressing FAI, ignoring the torsional profile of the femur. Similarly, the described ischiofemoral impingement or posteroinferior impingement may also be related to excessive antetorsion of the femur. ${ }^{29,30}$ Yet again, most authors describing a surgical approach for this condition do not even mention the femur torsional profile in their diagnostic algorithm.

At the present time, it is our impression that torsional deformities are not being addressed systematically in the decision algorithm of hip-preserving surgery, which may lead to inappropriate intra-articular bone resections as a way to solve extra-articular malalignment problems.

\section{Surgical Technique}

The two most frequently used approaches to treat FAI are open surgery with trochanteric osteotomy and arthroscopy. It is beyond the scope of this article to describe comprehensively the surgical techniques used to approach FAI. Instead we focus on the most recent evolution of certain surgical steps.

Hip arthroscopy is usually performed with the patient in the supine or lateral position under general anesthesia and proper muscle relaxation to allow for at least 10 to $15 \mathrm{~mm}$ of hip distraction. Care must be taken to protect the perineum, foot, and ankle soft tissues with adequate padding. Traction time must never extend more than 2 hours; ideally, it should be $<60$ minutes to prevent complications. ${ }^{31}$ Because hip joint structures are deep, the classic concept of portals location was replaced by a more generic concept of safe areas in the skin ${ }^{32}$ and proper portal location on the capsule. Portals must provide adequate visual control of the peripheral and central compartments and allow the possibility of performing acetabular rim and head-neck junction osteoplasty including the most lateral

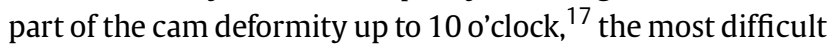
area to access in hip arthroscopy. ${ }^{25,33}$ Interportal and T-shaped capsulotomy is now accepted as a standard step in central compartment access because it allows a better exposure of the posterolateral/inferior aspects of the joint and nonconstrained manipulation of the instruments. ${ }^{34-37}$ Some published reports about cases of acute hip dislocation after large unrepaired capsulotomy $^{38-41}$ raised concerns about iatrogenic hip instability after arthroscopy, and some authors now recommend meticulous capsule closure in all cases. ${ }^{41-44}$

The next step in hip arthroscopy is to repair the labrum and cartilage lesions. Many techniques have been developed for this purpose. Regardless of the surgical option, the consensus is that the labrum should be repaired, when possible, and not resected. ${ }^{45-47}$ During labral refixation, articular penetration of suture anchors can occur. To avoid 
this complication, it is recommended to drill the tunnels from the anterolateral and the distal anterolateral portals. ${ }^{48}$ If rim trimming is necessary to resect the anterior acetabular wall and roof, meticulous preoperative planning is recommended to avoid excessive resection. Care must be taken in protrusio hips with a negative acetabular index and a large fossa, where removal of peripheral joint lunate surface can dramatically increase the transarticular contact forces, ${ }^{25}$ increasing the risk of degeneration. ${ }^{49,50}$ When performing arthroscopy in a mild dysplastic hip, it is also not advisable to resect the rim because it may create or increase a preexisting joint instability dramatically. Some authors argue for capsular plications on those patients, ${ }^{51}$ but no long-term results are available to support this technique, and the outcomes for acetabular reorientation after a failed arthroscopy seem to be worse. $^{52}$

Head-neck junction trimming should be performed with a motorized instrument starting from the equatorial area to the peripheral head-neck junction, avoiding deep localized perforations with the burr and notching of the cortical bone to prevent potential stress fractures ${ }^{53}$ or loss of joint sealing. A recent study established the safe margin of bone resection in the perforating area of retinacular vessels at a depth of $\sim 2.5 \mathrm{~mm}$ and $2 \mathrm{~mm}$ from the cartilage margin. ${ }^{18}$ The same study also reported the anterior limit of the vascular synovial fold lying more anteriorly than initially thought. It is advisable to be cautious when performing bone resection from the 1 o'clock to 10 o'clock areas of the head-neck junction (-Fig. 2). At the end of the procedure a flexion-internal rotation test is performed routinely to check for areas of residual impinging bone. If necessary, additional trimming should be performed.

Surgical hip dislocation is performed in lateral decubitus under general anesthesia and also with full muscle relaxation. Usually the surgeon approaches the hip using Gibson's interval

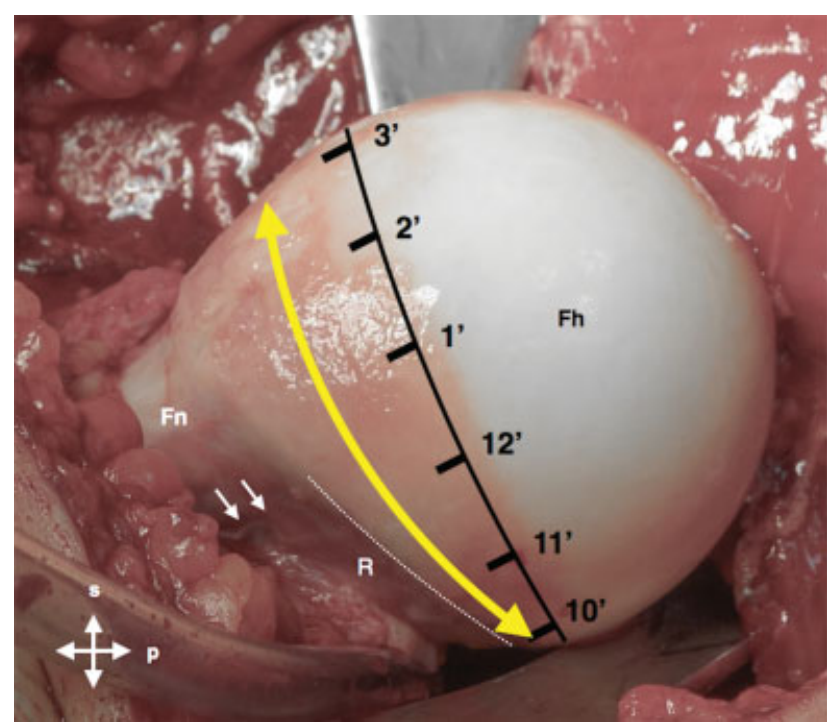

Fig. 2 Intraoperative picture of a femoral head showing a cam deformity (yellow arrow) overlapping the retinacular area (dotted line) on the posterosuperior aspect of the femoral head (from 12 to 10 o'clock). The two small arrows point to the anterior border of the retinacular synovial fold. Fh, femoral head; Fn, femoral neck; p, proximal; R, extension of the retinaculum; s, superior. with a fascia incision along the anterior border of the gluteus maximus, exposing the greater trochanter (GT) and the entire posterior region of the external rotators. ${ }^{54}$ To expose the deeper plan of the piriformis and gluteus minimus muscles, a trigastric trochanteric osteotomy (including all of the insertion of the vastus lateralis, most of the insertion of the gluteus medius, and the long head of the gluteus minimus) is performed.

A recent modification of this osteotomy with a step was described as an effective way to increase the stability of the fragment to speed union and rehabilitation. ${ }^{55,56}$ The next step is capsule exposure developing the interval between the piriformis and gluteus minimus muscles, and releasing the gluteus minimus from the capsule. At this time no dissection posterior to the piriformis should be performed to avoid potential interference with the femoral head vascular supply. The capsule should be incised along the axis of the femoral neck in the anterosuperior region, with an anterior and inferior extension parallel to the anterior intertrochanteric crest and a posteromedial extension close to the acetabular border, protecting the posterosuperior retinacular fold and the labrum. The anteroinferior extension of the capsulotomy should not extend into the medial area to protect the inferior vincular retinacular artery. ${ }^{57,58}$ The next step is dislocation of the femoral head by transecting the ligamentum teres, if needed, to access the central compartment.

Chondrolabral lesions can be accessed and treated. Labral lesions should be approached the same way as in arthroscopy. Femoral head osteoplasty can then be performed 360 degrees, respecting the superior retinaculum margins and the safe depth of resection recommendations in the vascular perforating area. ${ }^{18}$ Intraoperatively it is possible to test for full range of motion (ROM) before performing acetabular osteoplasty or to opt for a subtrochanteric derotation osteotomy if needed. ${ }^{59}$ Surgical hip dislocation also allows for a full labrum reconstruction using fascia lata, hamstrings tendons, or ligamentum teres. ${ }^{26,60}$ At the end of the procedure the capsule should be partially closed to avoid intra-articular increased pressure from cancellous bone bleeding. The step trochanteric osteotomy should then be fixed with two 3.5- or $4.5-\mathrm{mm}$ cortical screws.

\section{Long-term Results}

The number of studies reporting outcomes of FAI surgery is increasing, but there is a wide variation in patient-reported outcome measures (PROMs), and mean time of follow-up (FU) ranges from only 12 to 60 months. ${ }^{22}$ There are two studies with a minimum of 10 years FU time. One includes 97 hips and reports $80 \%$ survival rate after surgical hip dislocation considering as end points the need for conversion to total hip arthroplasty (THA), progression to osteoarthritis, and a Merle d'Aubigné-Postel score $<15 .{ }^{61}$ The other, including 145 patients, presents a survival rate of $66 \%$ after hip arthroscopy considering THA as the end point. ${ }^{62}$ The used outcome measures improved significantly in both studies. Other published series have a significant shorter FU time, but the overall time matched survival rate, and patient-reported outcomes are similar. ${ }^{23,63}$ The overall results seem promising, but reports 
of more consistent outcome measures are lacking. In fact, a recent meta-analysis review on FAI surgery results ${ }^{64}$ showed that the present literature is primarily focused on PROMs and diagnostic imaging, both reported in 93\% of the included studies. Objective parameters like hip strength and ROM were only reported in $2.5 \%$ and $24.5 \%$ of the studies, respectively.

Patient expectations regarding FAI surgery are generally higher than with THA, reflecting the younger age of the population and higher activity level. Mannion et al ${ }^{65}$ reported that before FAI surgery, $57 \%$ of the patients expected that their hip pain would be "much better"; $40 \%$ expected it would be "better," and $83 \%$ expected their ability to perform sports to be better or much better after surgery. In the same study, fulfillment of realistic expectations regarding improvement of pain and the ability to engage in sports activities were the most significant predictors of treatment effectiveness and higher global treatment outcomes.

Considering total hip replacement exclusively as the end point in a survivorship analysis of FAI, surgery might not be adequate because many patients are $<40$ years old, and probably their native hips would survive for many years even without surgery. ${ }^{66}$ It is imperative to create a better definition of what should be considered the failure mode of a hippreserving procedure. Beaulé et al proposed four different types of failure: progressive osteoarthritis, incorrect initial diagnosis or procedure, inappropriate correction, and surgical complications leading to further surgery. ${ }^{67}$ We believe that, in the future, not achieving some other objective parameters like ROM, muscle strength, or subjective parameters like the patient's expectations or improving certain PROMs should also be considered as valid end points to analyze hip-preserving surgery survivorship.

\section{What Do We Need to Know?}

\section{FAI Pathomorphology}

As previously stated, the two different types of impingement that often coexist in the same hip are cam and pincer impingement.

\section{Cam Impingement}

Cam impingement results from the presence of an abnormal osseous "bump" at the femoral head-neck junction. This occurs most commonly laterally and anteriorly, and more rarely at the posterior or inferior area of the head-neck junction. This protuberance can jam in the acetabular cavity through the normal ROM, particularly in flexion combined with internal rotation. Finite elements simulations ${ }^{68-71}$ showed that the major pathologic mechanism of cartilage damage in cam impingement is the increased contact pressure between the acetabular and femoral cartilage resulting from the inclusion of the head deformity in the nondeformable osseous acetabulum. The higher the distance from the femoral head center to a surface point of the cam deformity, the higher contact pressure of the two cartilage modeled surfaces at this point, ${ }^{72}$ meaning that cumulative abnormal contact pressure over the cartilage ${ }^{7}$ could represent the mechanical stimulus to joint damage. The repetitive compression cycles can cause chondrolabral junction separation, cartilage debonding from subchondral bone, and formation of a flap. Without treatment, this condition carries an increased risk of developing osteoarthritis. ${ }^{6,7}$

The labrum is usually involved later in this process because it contains a significant number of radial fibers with higher tensile properties (stiffness and strength) than the adjacent hyaline cartilage. ${ }^{73,74}$ The usual pattern of labral damage is chondrolabral avulsion. Occasionally, a stress fracture of the peripheral anterosuperior rim can occur or much less frequently a true labrum bone avulsion. ${ }^{7}$ In the early phases of impingement, a normal-appearing labrum on magnetic resonance imaging (MRI) does not exclude the presence of an important aggression to the joint cartilage caused by the osseous deformity. More recently, cam intrusion mechanism was described as occurring earlier in the arc of flexion. ${ }^{75}$ This indicates that patients with a cam deformity might have a higher risk than previously thought of developing hip impingement in routine activities like climbing stairs or even walking. These findings support the need for early diagnosis and treatment before irreversible damage to the joint occurs.

Cam deformity is not always visible on simple anteroposterior (AP) pelvis radiographs except if it extends laterally. Cross-table and Dunn 45-degree views (45 degrees of hip flexion and 20 degrees of abduction) can expose anterior or anterosuperior deformities, respectively. We consider those three incidences as the correct initial approach to cam impingement. Some additional views to inspect the 360degree head-neck junction waist ${ }^{76}$ and femoral neck torsion $^{77}$ were described, but those require leg holders and hence are difficult to make standard.

The standard clinical approach of the painful hip should include conventional radiographs for the quantification of basic parameters like centrum collum diaphyseal angle, the presence of a lateral or anterior osseous bump, a posterior head tilt, head-neck offset, and the presence of herniation pits ( $\mathbf{- T a b l e s} \mathbf{1}$ and $\mathbf{2}$ ). On the acetabular side, parameters related to spatial orientation and depth should also be reported.

When the articular space narrowing becomes visible on conventional radiographs, advanced osteoarthritic changes are usually already present. To assess the extension of joint damage, an MRI should always follow the radiographic studies. MRI radial sequences, introduced by Locher et al, ${ }^{78}$ have the advantage of defining the location in a face clock referential and quantifying the size of the cam deformity. Since then, the evolution of high-resolution MRI has improved the diagnostic accuracy of labrum and cartilage lesions and included even the possibility to identify and locate intra-articular vascular structures ${ }^{18}$ (-Fig. 3).

An effort has been made to clarify the location and extension of the cam protuberance. Nötzli et al described the $\alpha$ angle as a measure of the asphericity of the femoral head performed in axial oblique MRI images, parallel to the femoral neck axis. The $\alpha$ angle is usually measured in the radial plane where the cam deformity is most prominent, and it should not be higher than 50 degrees (-Fig. 4 and - Table 2). ${ }^{79}$ This parameter is the most used to quantify the 
Table 1 Common radiographic parameters useful in the diagnosis of femoroacetabular impingement

\begin{tabular}{|c|c|c|c|}
\hline & Parameter & Commonly used values & Comments \\
\hline \multicolumn{4}{|c|}{ Proximal femur } \\
\hline \multirow{3}{*}{$\begin{array}{l}\text { AP pelvis } \\
\text { radiographs }\end{array}$} & Column center angle & $120-140$ degrees $^{a}$ & $<120$ degrees: varus; $>140$ degrees: valgus \\
\hline & Trochanter position & $\begin{array}{l}\text { Tip at the level of } \\
\text { femoral head center }\end{array}$ & High-riding trochanter is a cause of extra-articular FAI \\
\hline & 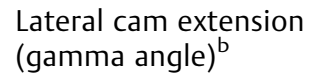 & $45-50$ degrees & Known as pistol-grip deformity \\
\hline \multirow{4}{*}{$\begin{array}{l}\text { Cross-table } \\
\text { view and } \\
\text { 45-degree } \\
\text { Dunn view }\end{array}$} & $\begin{array}{l}\text { Head-neck junction } \\
\text { anterior offset }^{\mathrm{b}}\end{array}$ & $>10 \mathrm{~mm}$ & Normal range values do not exclude $\mathrm{FAl}^{\mathrm{d}}$ \\
\hline & $\begin{array}{l}\text { Anterior cam extension } \\
(\alpha \text { angle })^{c}\end{array}$ & $45-50$ degrees & Normal range values do not exclude $\mathrm{FAl}^{\mathrm{d}}$ \\
\hline & Herniation pits & Absent & Found in cam-type FAI \\
\hline & $\begin{array}{l}\text { Anterior neck } \\
\text { cortical reaction }\end{array}$ & Absent & Found in pincer-type FAI \\
\hline \multicolumn{4}{|l|}{ Acetabulum } \\
\hline \multirow[t]{9}{*}{$\begin{array}{l}\mathrm{AP} \\
\text { radiographs }\end{array}$} & $\begin{array}{l}\text { Lateral center edge } \\
\text { angle of Wiberg }\end{array}$ & 25-39 degrees & $<25$ degrees: dysplasia; $>40$ degrees: overcoverage \\
\hline & Acetabular index angle & $0-10$ degrees & $<0$ degrees: overcoverage; $>10$ degrees: dysplasia \\
\hline & Ischial spine sign & \multirow[t]{2}{*}{ Absent } & \multirow[t]{2}{*}{ If present: acetabular retroversion sign } \\
\hline & Crossover sign & & \\
\hline & Posterior wall sign & Absent & If present: posterior wall insufficiency \\
\hline & Anterior wall index & $0.41(0.30-0.51)$ & \multirow[t]{2}{*}{ Not applicable in nonspherical femoral heads } \\
\hline & Posterior wall index & $0.91(0.81-1.14)$ & \\
\hline & Protrusio sign & Absent & If present: overcoverage \\
\hline & $\begin{array}{l}\text { Acetabulum } \\
\text { fossa position }\end{array}$ & $\begin{array}{l}\text { Lower than the lateral } \\
\text { edge of sourcil }\end{array}$ & If higher than the lateral edge of sourcil: protrusio \\
\hline $\begin{array}{l}\text { Faux profile } \\
\text { view }\end{array}$ & $\begin{array}{l}\text { Posteroinferior } \\
\text { joint space }\end{array}$ & - & If diminished: poor prognosis sign \\
\hline
\end{tabular}

Abbreviations: AP, anteroposterior; FAl, femoroacetabular impingement.

${ }^{a}$ According to Gilligan et al. ${ }^{150}$

${ }^{\mathrm{b}}$ According to Toogood et al. ${ }^{151}$

${ }^{\mathrm{c}}$ According to Nötzli et al. ${ }^{79}$

${ }^{\mathrm{d}}$ Normal anterior offset parameters do not exclude the presence of FAI because femoral neck torsion can contribute significantly to the occurrence of impingement.

amount of so-called asphericity of the femoral head. ${ }^{80}$ Special attention must be paid when measuring the $\alpha$ angle on the radial MRI. If the radial sequences are not centered on the geometric axis of the neck or if the angle is measured in an oblique axial plane, a gross underestimation error might result from this measurement. ${ }^{81}$ Bouma et al reported an interesting concept of using multiple parameters to define an impingement-free area on the femoral side: the omega zone. $^{82}$ The complexities of calculation necessary in this method make it difficult to use routinely for diagnosis and preoperative planning of FAI surgery. A simpler method of assessing the radial extension of the cam deformity, based on clinical radial MRI sequences, was described ${ }^{17}$ as a concept of a single angle: the omega angle (-Fig. 5).

The same authors also studied the intraosseous vascular structures in vivo and concluded that a significant number of hips presented an overlap of the deformed bone with the perforating vascular area of the superior retinaculum.
This correlation is particularly important because it can alter the surgeon's decision about whether to resect bone in an area more difficult to access and therefore influence the surgical approach. Radial MRI sequences should address this aspect. The same omega angle can be calculated in reformatted computed tomography (CT) or MRI scans using a more precise semiautomated method. ${ }^{83} \mathrm{CT}$ scan, however, ignores soft tissues and vascular structures, and we recommend against using it as a single surgery planning tool of FAI but rather regard it as a complementary tool.

With the understanding that femoral neck torsion has a very important role in determining the impingement mechanism, ${ }^{9}$ the femur torsional profile must be reported as part of the diagnostic algorithm of a painful hip. A low femoral antetorsion alone or combined with a mild cam deformity might be responsible for a symptomatic severe limitation of hip flexion and internal rotation that may need 
Table 2 Common MRI parameters useful in diagnosis of femoroacetabular impingement morphology

\begin{tabular}{|c|c|c|c|}
\hline & Parameter & Common findings & Comments \\
\hline \multicolumn{4}{|l|}{ Proximal femur } \\
\hline \multirow[t]{4}{*}{ Radial MRI } & $\begin{array}{l}\text { Cam deformity } \\
\text { ( } \alpha \text { angle) }\end{array}$ & $\begin{array}{l}45-50 \text { degrees } \\
\text { at } 3 \text { o'clock }\end{array}$ & $\begin{array}{l}\text { Should be measured in the radial plane where the } \\
\text { deformity is more prominent }\end{array}$ \\
\hline & Omega angle & Absent $^{\mathrm{a}}$ & Not measurable in hips without cam deformity \\
\hline & Herniation pits & Absent & If present, generally occurring in cam deformity area \\
\hline & $\begin{array}{l}\text { Bone apposition } \\
\text { on the neck }\end{array}$ & Absent & If present, consider a sign of pincer impingement \\
\hline Coronal sequences & Labrum size at 12 o'clock & $5 \mathrm{~mm}^{\mathrm{b}}$ & If larger, interpret as a sign of potential instability \\
\hline Axial sequences & Torsion of the neck ${ }^{c}$ & $10-20$ degrees & \\
\hline \multicolumn{4}{|l|}{ Acetabulum } \\
\hline \multirow[t]{2}{*}{ Radial MRI } & $\begin{array}{l}\text { Cartilage softening/ } \\
\text { delamination }\end{array}$ & Absent & If present, radial extension should be documented ${ }^{d}$ \\
\hline & Labral lesion & Absent & If present, radial extension should be documented ${ }^{d}$ \\
\hline Coronal sequences & $\begin{array}{l}\text { Ligamentum } \\
\text { teres lesion }\end{array}$ & Absent & \\
\hline
\end{tabular}

${ }^{a}$ Omega angle measures the radial extension of the deformity. In normal hips it is not measurable. ${ }^{17}$

${ }^{b}$ In the transverse plane.

${ }^{\mathrm{c}}$ Related to the condylar axis. ${ }^{151}$

dPrognostic determinants.

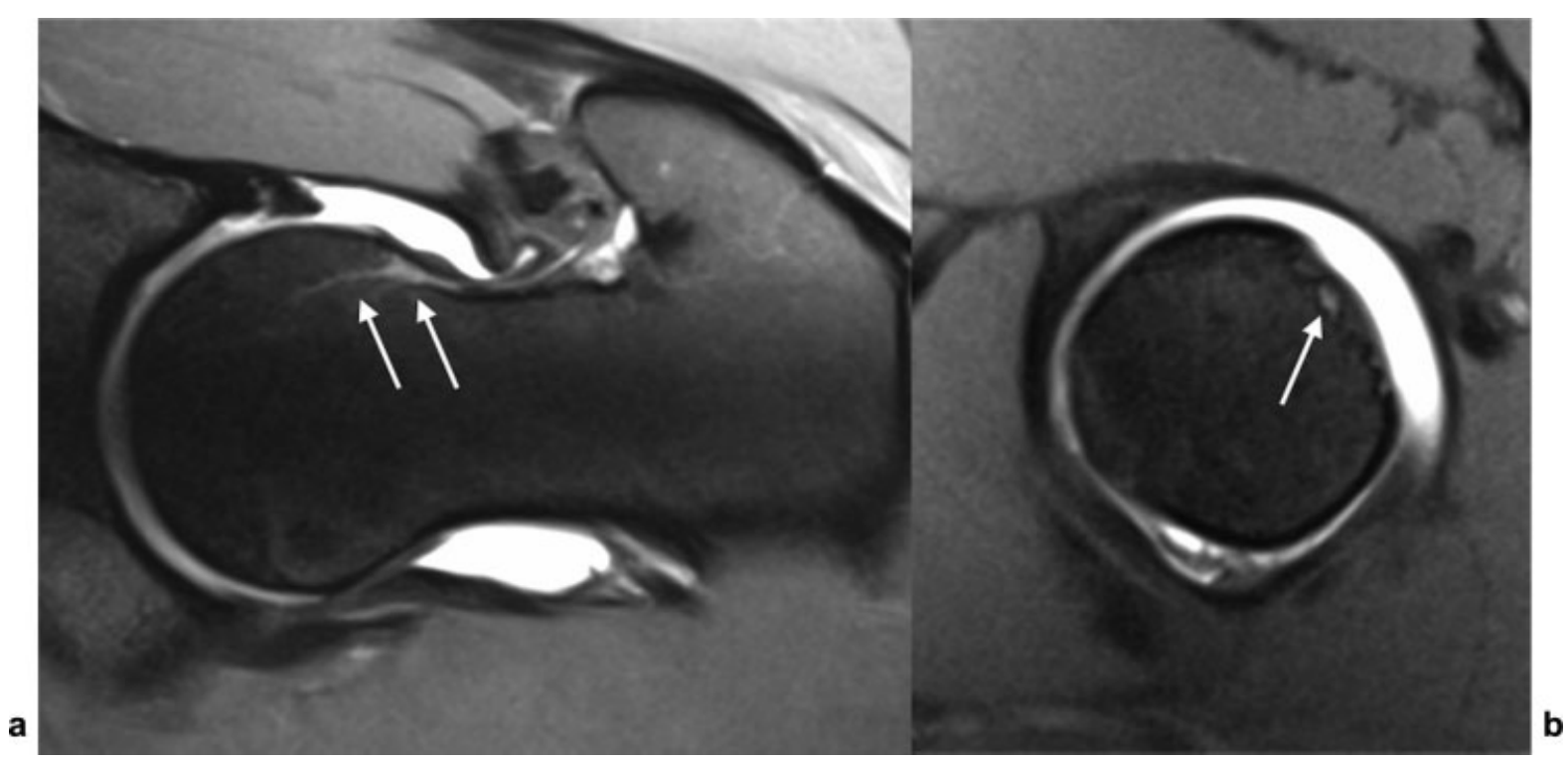

Fig. 3 (a) Radial magnetic resonance image showing one retinacular artery (arrows) perforating the femoral head bone. (b) The same vessel (arrow) visible in the posterosuperior quadrant in a short neck axis plane, perpendicular to the femoral neck.

to be addressed with a head-neck junction osteoplasty and a derotational osteotomy instead of an isolated hip arthroscopy.

\section{Pincer Impingement}

Pincer impingement mechanism is due to an abnormal contact between the acetabular rim and the femoral neck. Predisposing conditions include focal overcoverage, global acetabular retroversion, and general acetabular overcoverage (protrusio hips). Femoral neck retrotorsion when combined with any of the previous conditions also contributes to the occurrence of pincer impingement. The repeated impac- tion leads to progressive damage of the labrum and chondrolabral junction. The labrum is compressed between the femoral neck and the underlying bone, and the force is further transmitted to the acetabular cartilage. ${ }^{6,7}$ In focal or global acetabular retroversion, impingement usually occurs in the anterosuperior area of the rim, whereas in protrusio hips the area of impingement is wider and circumferential. In all situations, forced flexion will leverage the femoral head from the acetabulum, increasing the pressure between the posteromedial aspect of the femoral head and the posteroinferior acetabulum leading to a countercoup lesion. ${ }^{6}$ The repetitive microtrauma leads to direct labral 


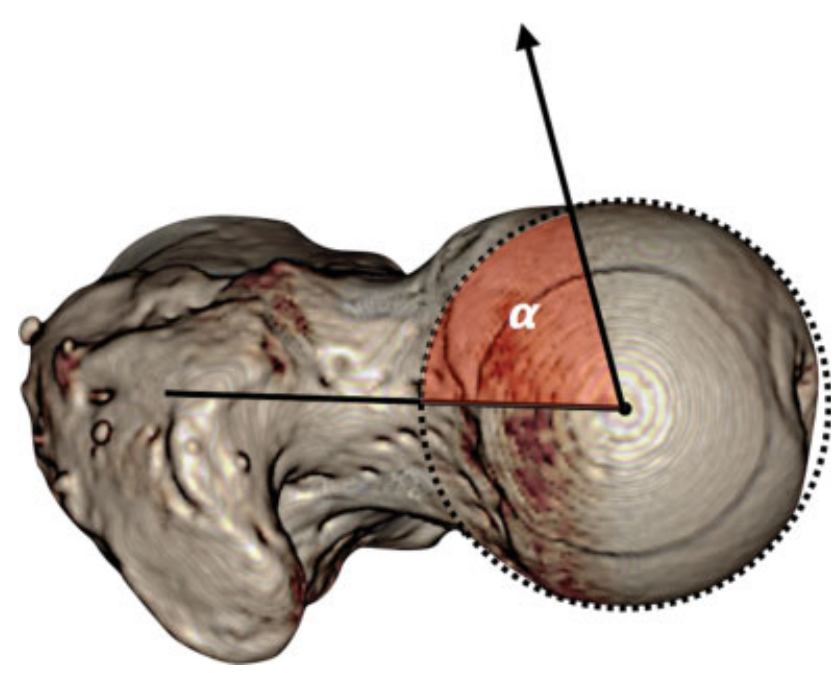

Fig. 4 Alpha angle $(\alpha)$ is defined accordingly to Nötzli et al $^{79}$ as the intersection of two lines at the center of the femoral head: one coincident with the central femoral neck axis and the other intersecting the circumference of the femoral head at the point where it stops being spherical. The normal value is considered to be below 50 degrees. The drawing shows a pathologic $\alpha$ angle of 70 degrees.

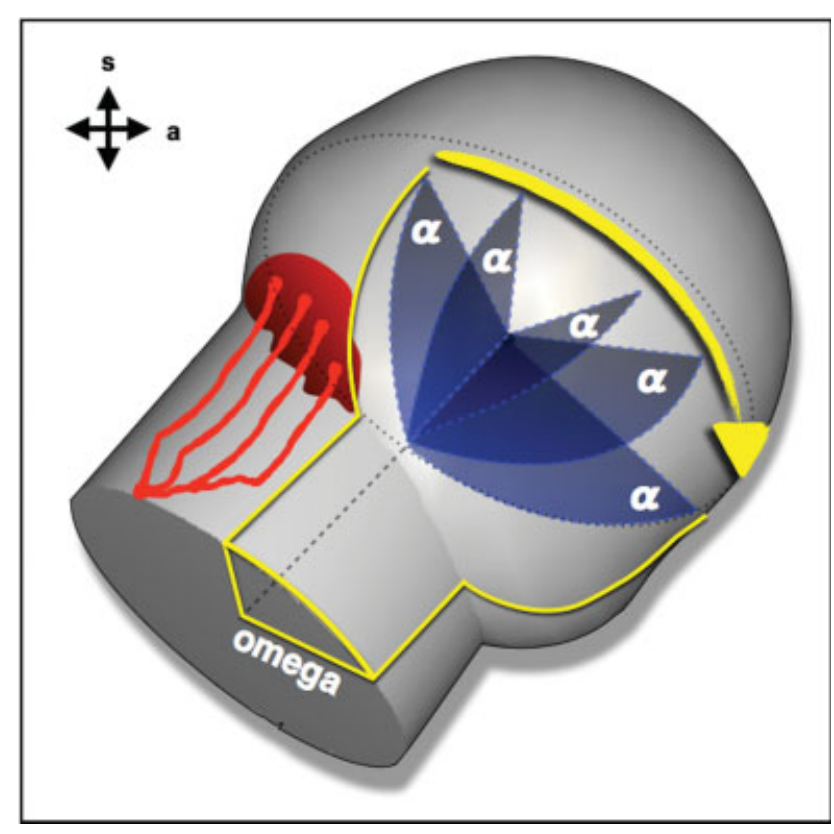

Fig. 5 The Omega angle is defined as the radial extension of a cam deformity. ${ }^{17}$ It encompasses all the radial plans where the $\alpha$ angle is above the normal value. In the drawing the red structures represent retinacular arteries. a, anterior; s, superior.

damage compromising the normal joint sealing effect, shock absorption, and pressure distribution.

The most frequent pathologic findings in this situation are intrasubstance cystic degeneration and tears. Intraoperatively, the labrum usually appears bruised, flattened, and has lost its normal elastic consistency. ${ }^{84,85}$ Pincer impingement may lead to bone growth at the base of the labrum that subsequently ossifies and may progressively increase acetabular coverage. ${ }^{6}$ The femoral head-neck junction frequently exhibits a linear depression and secondary ossification due to the repeated impact in the acetabular rim $^{86}$ ( $\mathbf{- F i g . 1}$ ). The loss of mechanical support from the labrum may result in higher contact forces, loss of cartilage nutritional supply, increased risk of chondral matrix breakdown, and ultimately joint degeneration. ${ }^{87}$ Cartilage damage is secondary to labrum aggression and usually confined to a narrow band along the rim and coincident with areas of labral damage. Additional Posteroinferior roughening or fibrillation can occur in up to a third of the cases. Posteroinferior femoral head cartilage damage can also be present in more than half of the cases. ${ }^{6}$

When evaluating pincer morphology, the most relevant morphological parameters of the acetabulum that should be quantified on simple AP pelvis radiographs are acetabular index (AI) angle, lateral center edge (LCE) angle of Wiberg, anterior and posterior wall indexes ${ }^{88}$ ( - Fig. 6), crossover sign, and ischial spine $\operatorname{sign}^{89}$ (-Fig. 7). Faux profile incidence of the hip is also used to assess the posteroinferior aspect of the joint that in pincer impingement can show early narrowing as the result of countercoup lesion, a sign of a poor prognosis. ${ }^{3,6}$

Focal retroversion is defined as a posterior opening of the most proximal portion of the acetabular socket with the anterior acetabular rim lying more lateral than the posterior rim in the cranial aspect of the acetabulum. There is a normal relation of the anterior and posterior walls distally and normal posterior coverage. ${ }^{90,91}$ In the standard AP pelvis radiograph, this is visible as the crossover sign ( - Fig. 7) where the crossing point between the anterior and posterior walls indicates the limit superior to which the acetabular opening is posterior. In this case, trimming the rim and refixing the labrum should be enough to address the anterior pincer mechanism.

Acetabular global retroversion describes a torsional deformity where the acetabular contact area is within the normal limits, but there is proximal anterior overcoverage and posterior wall insufficiency. ${ }^{14,88}$ Crossover sign, ischial spine sign (prominent ischial spine projecting into the pelvic inlet), and posterior wall sign (posterior wall stands medial to the center of the femoral head) are usually present in this deformity because it results from a rotational malorientation of the whole hemipelvis. ${ }^{89,90,92}$ In some cases the anterior overcoverage combined with posterior coverage deficiency can lead to anterior impingement and posterior instability due to a leverage effect of the femoral neck against the anterior rim not opposed by a sufficient posterior contact surface. ${ }^{93-95}$ To address this deformity, an acetabular reorientation procedure is the rational option. According to Zurmühle et al, ${ }^{96}$ it yields better long-term results than isolated rim trimming ( - Fig. 8). Caution is necessary when evaluating the radiographic signs of retroversion because malrotation of the pelvis in the horizontal or sagittal plane will substantially alter them. ${ }^{97,98}$ The variable morphology of the anteroinferior iliac spine (AIIS) can also contribute to the appearance of the crossover sign in a normal anteverted acetabulum. ${ }^{93}$

General acetabular overcoverage is caused by a deep acetabulum with excessive acetabular coverage and prominent walls. The LCE angle is typically superior to 40 degrees, the anterior and posterior wall indexes are increased, ${ }^{99,100}$ and the AI angle equals or is inferior to zero. ${ }^{24}$ Protrusio acetabulum is considered to be a deep socket characterized 


\section{a}
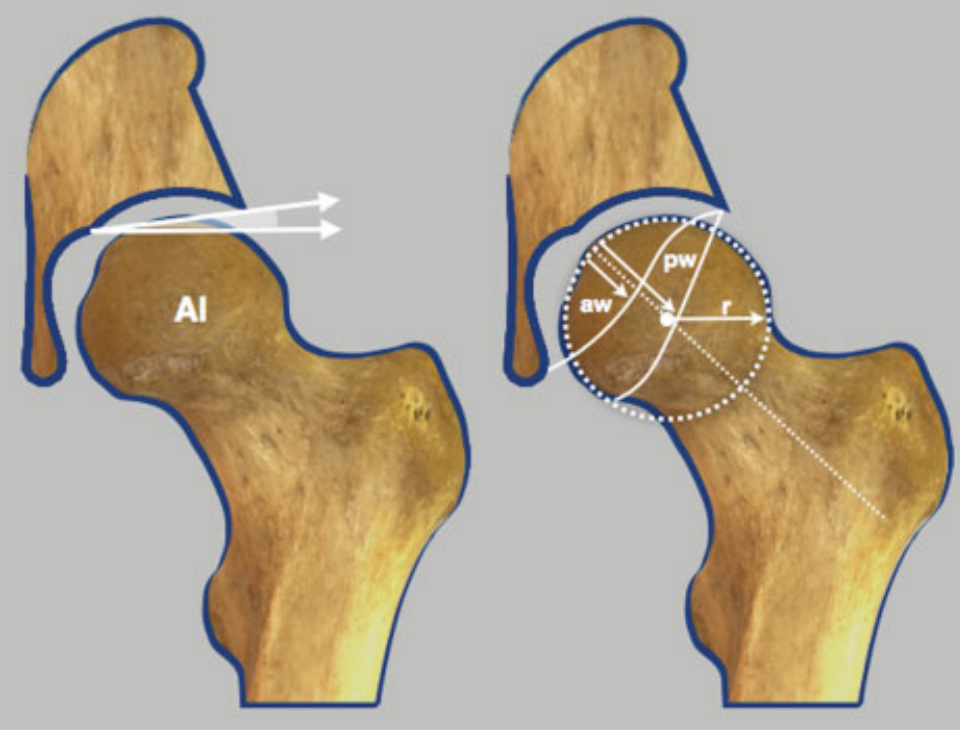

b, $\mathbf{c}$

Fig. 6 (a) Lateral center edge (LCE) angle is formed by two lines crossing the center of the femoral head, one perpendicular to the transverse plane of the pelvis and the other crossing the lateral limit of the sourcil. Normal values vary from 25 degrees to 40 degrees. Values greater than 40 degrees define acetabular overcoverage and less than 25 degrees of dysplasia, according to Wiberg. (b) Acetabular index (Al) angle is formed by a line in the transverse plane of the pelvis and a line connecting the medial end of the sourcil with the lateral limit of the acetabular roof. Normal values vary from 0 to 10 degrees. Values greater than 10 degrees suggest acetabular dysplasia according to Tönnis. ${ }^{152}$ Negative values are typical of acetabular overcoverage and protrusio hips. (c) Representation of anterior and posterior acetabular walls projection. To calculate the acetabular walls index, the best fit circle to the femoral head contour is drawn. The radius $(r)$ of the femoral head is determined, and the distance from the medial edge of circle to the anterior (aw) and posterior (pw) walls along the femoral neck axis line is measured. The anterior wall index (awi) and posterior wall index (pwi) are calculated as aw/r and pw/r, respectively. The values for normal hips are awi $=0.41(0.30-$ $0.51)$ and pwi $=0.91(0.81-1.14)$, according to Siebenrock et al. ${ }^{88}$

by a medial overlap of the femoral head with the ilioischial line, a larger and higher acetabular fossa with a normal-size lunate articular surface. Coxa profunda, defined as the acetabular fossa touching or projecting medially to the ilioischial line, should not be used as a radiographic marker of pincer

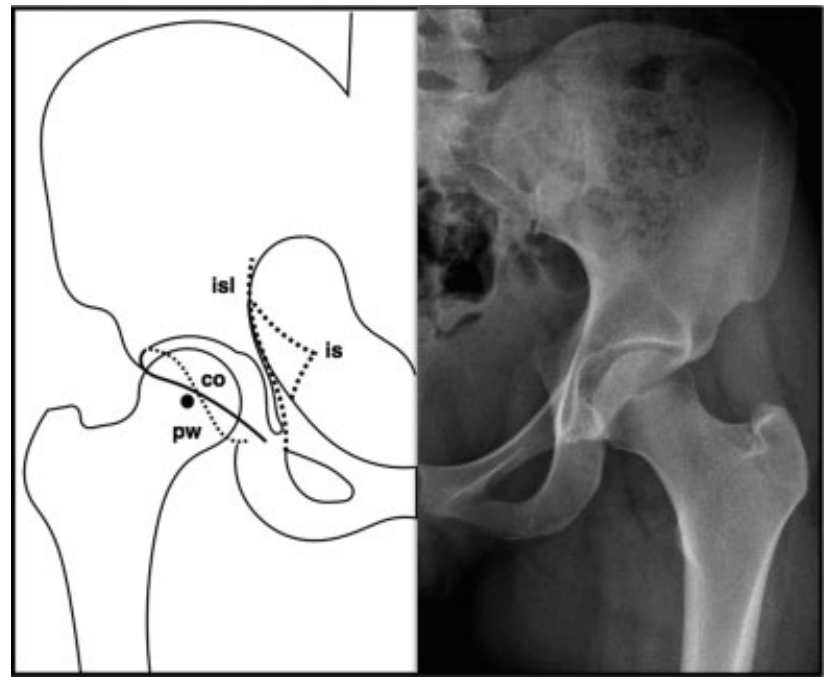

Fig. 7 Anteroposterior pelvic radiograph of a 20-year-old woman showing the classic signs of acetabular retroversion. The anterior wall line crosses the posterior wall line (dotted) creating a figure of eight or crossover sign (co); the posterior wall lies medial to the femoral head center of rotation creating the posterior wall sign (pw); the ischial spine projects into the pelvis creating the ischial spine sign (is). The vertical dotted line (isl) represents the ilioischial line. impingement because it can be found in hips with normal radiographic parameters and also in acetabular dysplasia. ${ }^{101,102}$ Similar to global retroverted hips, isolated acetabular rim trimming could be disadvantageous in protrusio hips where the lunate surface usually presents a normal size. Performing an extended rim trimming to lower the LCE angle and wall indexes to normal values can reduce the weightbearing area dramatically, leading to early osteoarthritis. ${ }^{49,50}$ Deep hips, however, present with a large variation of the proportional size of the lunate surface to the acetabular fossa. The surgical approach in this case should be decided on an individual basis. Hips with a larger lunate surface and a relatively smaller acetabular fossa might benefit from acetabular rim trimming. If the lunate surface presents a normal size along with a large fossa and a negative AI angle, a reorientation procedure combined with limited rim trimming might be a rational choice (- Fig. 9). ${ }^{49,99}$

\section{Refining the Concept of Instability and Impingement}

Our understanding of hip biomechanics has advanced significantly in the last 2 decades. ${ }^{103}$ Although there is much more work to be done, it is now clear that if inflammatory arthropathies and traumatic conditions are excluded, the hip joint can fail by two basic pathomechanisms: instability ${ }^{104}$ and impingement. ${ }^{7}$ Although there is no doubt that hips can exhibit both pathomechanisms, we must first clearly define what represents instability versus impingement if we are to optimize our management strategies ${ }^{67}$ as well as properly define the natural history of these conditions. 


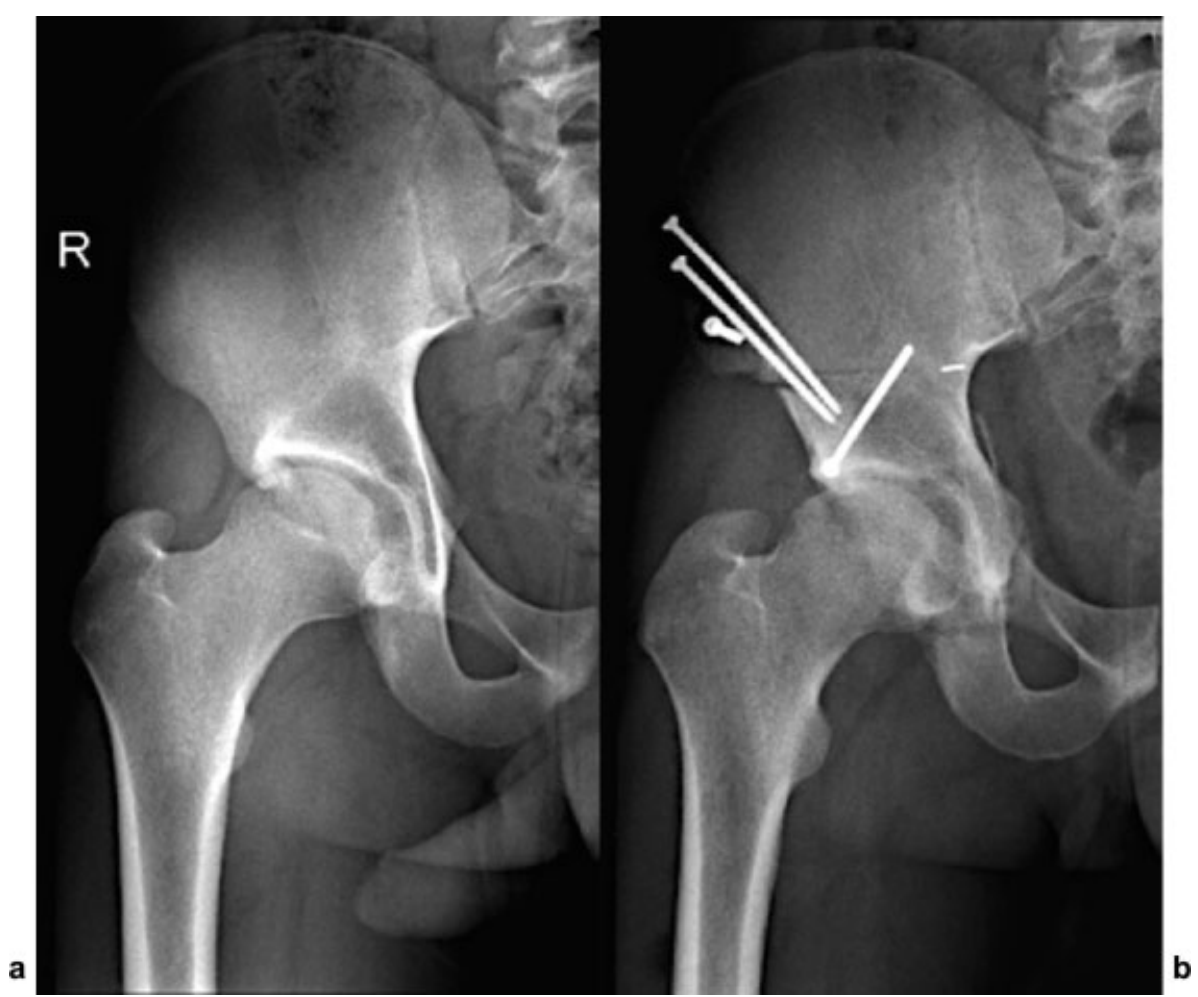

Fig. 8 Pelvic radiograph of a 22-year-old male patient showing a global acetabular retroversion on the right hip. (a) Before surgery we can identify the crossover sign, the posterior wall sign, and the ischial spine sign. (b) After a reversed periacetabular osteotomy surgery, the crossover sign and the posterior wall sign have disappeared.

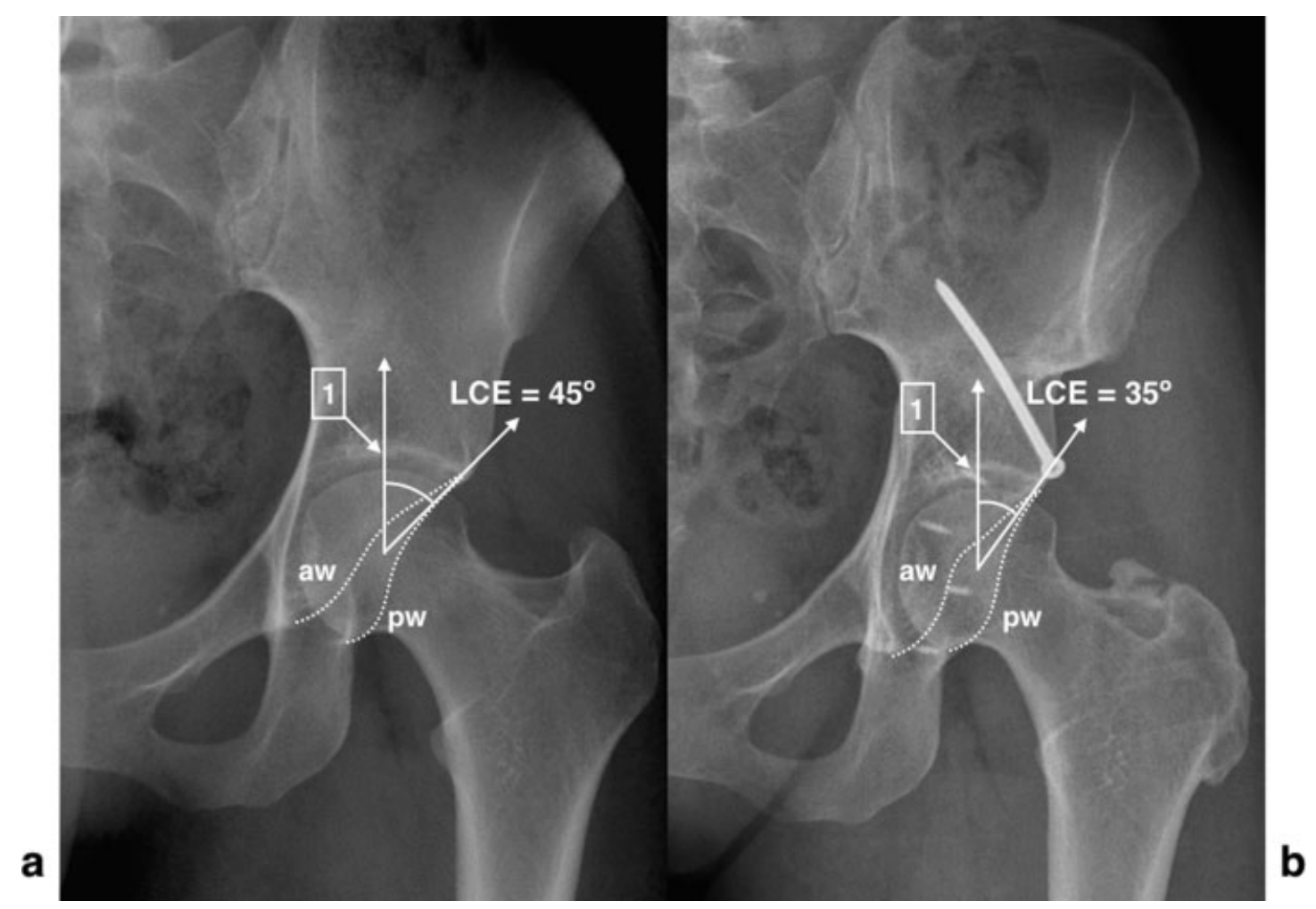

Fig. 9 Pelvic radiograph of a 27-year-old female patient showing general acetabular overcoverage. (a) Before surgery we can identify the increased lateral center edge angle (LCE), the negative acetabular index angle, the higher than normal position of the acetabular fossa (1), and increased anterior (aw) and posterior wall (pw) indexes. (b) After reversed periacetabular osteotomy plus surgical hip dislocation, acetabular rim trimming and relative neck lengthening, the acetabular coverage angle (LCE) has been decreased and the lateral limit of the acetabular fossa lies more medially. The posterior wall is still lateral to the center of rotation because the smaller relative size of the lunate surface contraindicates excessive rim trimming of the posterior wall. 


\section{Impingement}

Biomechanically, the native hip has long been thought of as a simple ball-and-socket joint. However, it is now clear that this concept is overly simplistic. As first proposed by Menschik in $1997,{ }^{105}$ the shape of the femoral head is more conchoid than spherical in that its geometric and functional center of rotation differs. As a result, there will normally be sliding/translational movement of the femoral head within the acetabulum in addition to pure rotation. ${ }^{106}$ In addition to intra-articular anatomy, the "cone" of movement within which the hip functions is further dictated by extra-articular parameters including the proximal femoral anatomy, pelvic anatomy, and spinopelvic alignment and kinematics. ${ }^{107}$ These native design features inherently allow a certain degree of "natural" impingement without causing irreversible cartilage damage. ${ }^{108}$

On the femoral side are certain degrees of femoral head asphericity, as measured by the $\alpha^{79}$ and omega ${ }^{17}$ angles that will inevitably lead to impingement. However, a recent study clearly demonstrated the likely interaction between femoral head asphericity and other variables that leads to pathologic impingement, such as acetabular coverage angles, pelvic incidence, and femoral neck/shaft angle. ${ }^{109}$ The localized overload of the joint in the region of impingement leads to stiffening of the subchondral bone plate ${ }^{110}$ and eventual outside/inside damage of the articular surface. ${ }^{6}$

Impingement can also take place when there are extraarticular femoral and/or pelvic deformities such as torsional abnormalities or a prominent AIIS, respectively. ${ }^{111,112}$ Although strong evidence indicates that extra-articular impingement can negatively impact function and quality of life, a causal link to degenerative arthritis of the hip is much less conclusive. Lastly, the role that dynamic spinopelvic kinematics play in impingement and resulting symptoms was only recently explored. ${ }^{113,114}$

Regarding acetabular-based deformities that lead to impingement (i.e., pincer), thinking has evolved. ${ }^{3}$ The classic example of pincer impingement is acetabular protrusio where overcoverage is defined on the AP pelvic radiograph as the femoral head touching and/or crossing the ilioischial line. More recently, less severe forms were also described (i. e., coxa profunda and focal acetabular retroversion). ${ }^{6}$ Although there was initial support for this classification of acetabular-based impingement, recent work has somewhat dispelled this concept. First, both Nepple et al ${ }^{102}$ and Anderson et al ${ }^{101}$ reported that coxa profunda radiographic characteristics are commonly seen in patients with hip dysplasia and thus cannot be relied on to diagnose acetabular overcoverage. Zaltz et $\mathrm{al}^{93}$ also showed that the crossover sign is not specific to acetabular retroversion and rather may be seen with varying morphologies of the AIIS. More importantly, recent anatomical and CT-based studies demonstrated that acetabular retroversion in its pathologic form is truly a maldevelopment of the lower hemipelvis (i.e., a dysplastic acetabulum). ${ }^{115,116}$ Consequently, we would argue that acetabular retroversion is less a problem of impingement and more likely a form of instability.
Overt instability of the native hip secondary to acetabular dysplasia has long been recognized in the pediatric literature and often depends on the degree of acetabular and femoral deformity ${ }^{117}$ Excluding traumatic causes, gross instability (i.e., dislocation) of the hip joint in adults is rare, although it can be seen in patients with connective tissue disorders (e.g., EhlersDanlos syndrome) or secondary to excessive capsular resection and/or acetabular rim trimming after arthroscopic surgery. ${ }^{38}$

The term subclinical instability is more applicable to adult hips that do not show overt dislocation yet likely exhibit an abnormal loading characteristic that can lead to early degenerative change. ${ }^{118}$ Specifically, the joint reaction force in these hips is directed closer to the acetabular rim rather than being contained more medially within the acetabulum. ${ }^{106}$ The resultant force concentration at the acetabular rim first leads to failure of the labrum followed by progressive arthritic changes. ${ }^{119}$ This process is most evident in socalled classic hip dysplasia in which lateral acetabular coverage is reduced and can be identified by a decreased LCE angle on the AP pelvic radiograph.

However, the LCE angle measures only lateral coverage. Anterior and posterior acetabular deficiencies were also well described $^{90,120}$ and quantified using a CT-based method that estimates the amount of coverage of the femoral head (anterior and posterior wall percentage covered). ${ }^{116,121}$ As a result, we believe that acetabular coverage and the definition of hip dysplasia cannot be restricted to lateral coverage (i.e., LCE angle) alone. We would propose that deficient three-dimensional (3D) acetabular coverage is almost always the primary anatomical abnormality in the dysplastic hip. ${ }^{122}$ Furthermore, this 3D coverage deficiency can be due to either anatomical or functional/postural malorientation of the acetabulum.

In that regard, a more comprehensive classification for hip dysplasia was proposed based on the likely direction of instability as evidenced by the location of acetabular deficiency, the Ottawa classification ( - Table 3). ${ }^{123}$ By understanding the likely direction of instability, this classification also assists in surgical planning for redirectional acetabular osteotomies.

In trying to understand the anatomical geometry and biomechanical function of the hip, it is important to recognize various patterns of hip failure. The two basic pathomechanisms of hip degeneration, as stated earlier, are impingement and instability. Impingement results from premature/abnormal contact between the proximal femur and pelvis, whereas instability is a result of altered acetabular geometry leading to subclinical instability and abnormal joint reaction force. Appreciation of these definitions and their mechanisms of hip failure will assist the treating physician appropriately in the management of bone abnormalities and concomitant chondrolabral lesions.

\section{Labrum and Cartilage Lesions}

\section{Labrum}

The labrum is a fibrocartilaginous structure anchored circumferentially to the bony acetabular rim and adherent to the articular cartilage, and it blends into the transverse 
Table 3 Ottawa classification of hip dysplasia

\begin{tabular}{|c|c|c|}
\hline & Parameter & Comments \\
\hline \multicolumn{3}{|c|}{ Global/Lateral deficiency } \\
\hline $\begin{array}{l}\text { AP pelvis } \\
\text { radiographs }\end{array}$ & $\begin{array}{l}\mathrm{LCE}<20 \text { degrees } \\
\text { or } \\
\mathrm{LCE}>20 \text { degrees and } \\
<25 \text { degrees and } \\
\mathrm{Al}>10 \text { degrees }\end{array}$ & $\begin{array}{l}\text { "Traditional" dysplastic hips in the literature based on just LCE measurements } \\
\text { Anterior or posterior undercoverage depending on acetabular version }\end{array}$ \\
\hline \multicolumn{3}{|c|}{ Anterior deficiency } \\
\hline $\begin{array}{l}\text { AP pelvis } \\
\text { radiographs }\end{array}$ & $\begin{array}{l}\mathrm{LCE}>25 \text { degrees and } \\
\mathrm{PAC}<15 \% \text { or } \\
\mathrm{AWI}<0.30\end{array}$ & $\begin{array}{l}\text { No lateral deficiency } \\
\text { Negative crossover and posterior wall sign } \\
\text { Possible excessive posterior wall coverage } \\
\text { In PAC }<15 \% \text { and PPC }<36 \% \text { hips: anteriorly deficient if retroversion signs absent }\end{array}$ \\
\hline \multicolumn{3}{|c|}{ Posterior deficiency } \\
\hline $\begin{array}{l}\text { AP pelvis } \\
\text { radiographs }\end{array}$ & $\begin{array}{l}\mathrm{LCE}>25 \text { degrees and } \\
\mathrm{PPC}<36 \% \text { or } \\
\mathrm{PWI}<0.80\end{array}$ & $\begin{array}{l}\text { No lateral deficiency } \\
\text { Positive posterior wall and ischial spine sign } \\
\text { In } \mathrm{PAC}<15 \% \text { and } \mathrm{PPC}<36 \% \text { hips: posteriorly deficient if retroversion signs present }\end{array}$ \\
\hline
\end{tabular}

Abbreviations: Al, acetabular index angle; AP, anteroposterior; AWI, anterior wall index; LCE, lateral center edge (angle of Wiberg); PAC, percentage anterior coverage; PPC, percentage posterior coverage; PWI, posterior wall index.

Table 4 Common findings in extra-articular FAl and preferred surgical approach

\begin{tabular}{|l|l|l|l|l|l|l|l|l|}
\hline ExFAI & Instability & $\begin{array}{l}\text { Mechanical } \\
\text { impingement }\end{array}$ & $\begin{array}{l}\text { Articular } \\
\text { damage }\end{array}$ & $\begin{array}{l}\text { Functional } \\
\text { limitation }\end{array}$ & Developmental & Traumatic & Approach & Procedure \\
\hline SI type 1-2 & No & Yes & Yes & No & Yes & No & Arthroscopy & $\begin{array}{l}\text { Labral } \\
\text { refixation }\end{array}$ \\
\hline SI type 3 & No & Yes & No & Yes & No & Yes & Arthroscopy & AllS resection \\
\hline Trochanteric & No & Yes & Yes & Yes & Yes & No & Open & GT resection \\
\hline $\begin{array}{l}\text { Femoral } \\
\text { antetorsion }\end{array}$ & Yes & No & Yes & Yes & Yes & Yes & Open & $\begin{array}{l}\text { Femoral } \\
\text { osteotomy }\end{array}$ \\
\hline $\begin{array}{l}\text { Femoral } \\
\text { retrotorsion }\end{array}$ & No & Yes & Yes & Yes & Yes & Yes & Open & $\begin{array}{l}\text { Femoral } \\
\text { osteotomy }\end{array}$ \\
\hline $\begin{array}{l}\text { IF } \\
\text { impingement }\end{array}$ & Yes & Yes & No & Yes & Yes & No & $\begin{array}{l}\text { Open/ Arthroscopy } \\
\text { Destabilization }\end{array}$ \\
\hline
\end{tabular}

Abbreviations: AlIS, anterior inferior iliac spine; ExFAI, extra-articular femoral acetabular impingement; GT, greater trochanter; IF, Ischiofemoral; $\mathrm{LT}$, lesser trochanter; SI, subspine.

acetabular ligament overlying the cotyloid notch at the 6 o'clock position. ${ }^{124,125}$ The labrum functions as a seal to allow containment of synovial fluid for lubrication that then provides nutrition and a low coefficient of friction to the joint surface, as well as stability. ${ }^{124-126}$

A recent survey of high-volume hip arthroscopy surgeons found that most cite MRI as the most influential preoperative tool to guide how they manage the labrum intraoperatively. ${ }^{127}$ The following are MRI characteristics that the hip surgeon wants an assessment for regarding labrum pathology.

\section{Type of Labral Tear}

The type of tear described on MRI is helpful in operative planning because it can influence the surgical management strategy that may include labral debridement, repair, or reconstruction. Seldes et al described two distinct labral tear patterns based on anatomical and histologic features that have been adopted by most hip surgeons: chondrolabral separation (type 1) and intrasubstance tear (type 2). ${ }^{124}$ Type 1 tears are detachments of the labrum from the articular cartilage surface. These tears occur at the transition zone between the fibrocartilaginous labrum and articular hyaline cartilage. They are perpendicular to the articular surface and, in some cases, extend to the subchondral bone. Type 2 tears consist of one or more cleavage planes of variable depth within the substance of the labrum.

Many MRI reports comment on the tear depth as complete or partial thickness. The depth of the tear has limited influence on how the labrum will be managed surgically. The diagnosis of chondrolabral separation reveals an association with cam-type FAI and directs the surgeon to evaluate bone morphology concurrently with labrum pathology. In contrast, intrasubstance degeneration or cleavage-type tears may suggest an evaluation of pincer-type FAI morphology (-Fig. 10). A detailed assessment of tissue quality is also helpful in determining whether the labral tissue is viable for a primary repair. For example, degenerative changes such as cystic changes or attenuation of tissue may prompt the surgeon to consider a labral reconstruction procedure in the appropriate patient. 

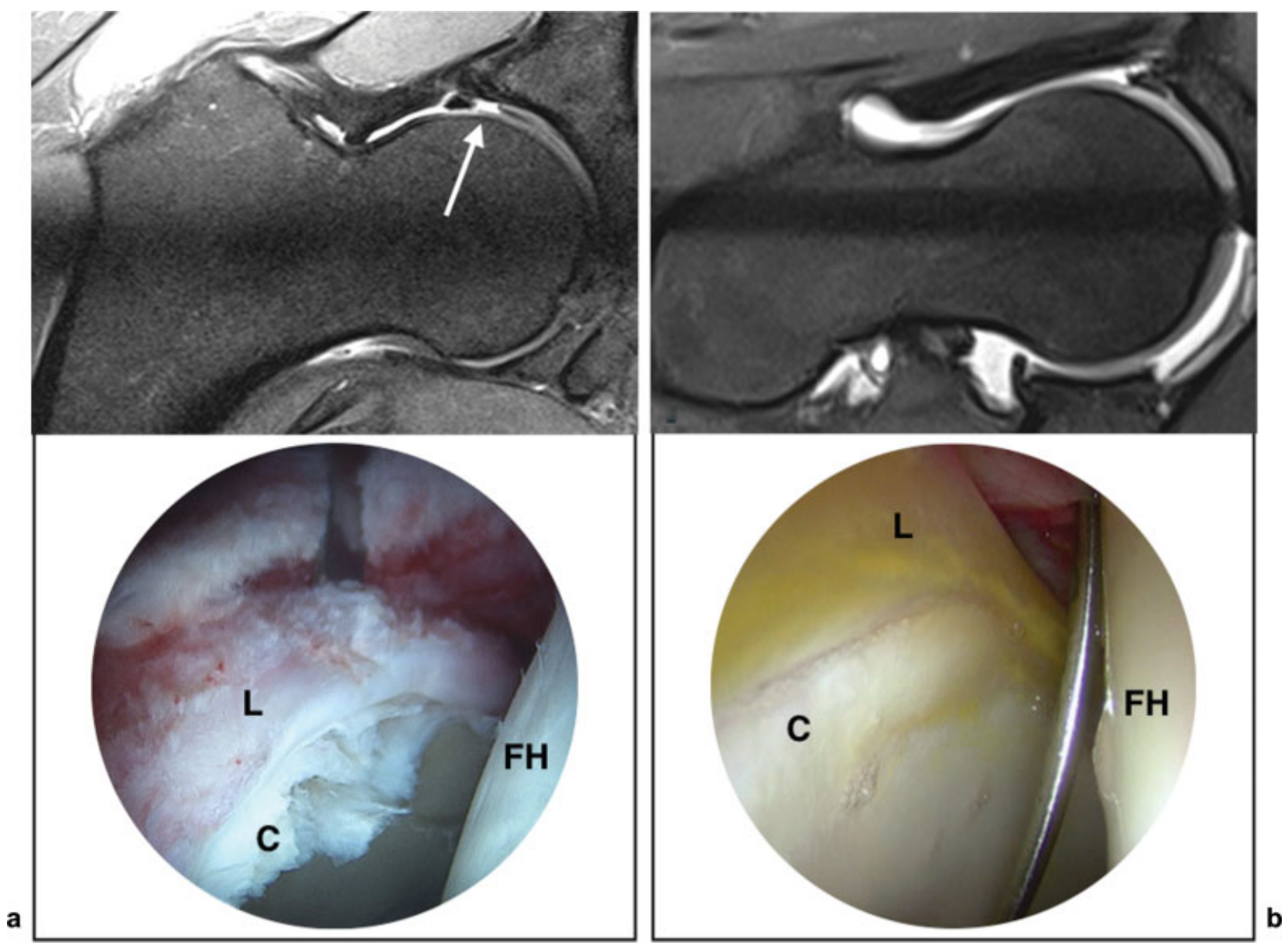

Fig. 10 (a) MRI radial plane at 1 o'clock of a 25-year-old man with cam impingement. Imaging shows severe cartilage debonding from subchondral bone and chondrolabral disruption. Below, the intraoperative aspect of the same case where the cartilage presents gross fibrillation and complete avulsion from the labrum and subchondral bone. (b) MRI radial plane at 2 o'clock of a 40-year-old woman with pincer impingement. Imaging shows an hypoplastic labrum and limited altered signal of the adjacent cartilage without chondrolabral separation. Below, the intraoperative aspects of the same case showing an hypoplastic labrum and less severe cartilage damage. C, cartilage; FH, femoral head; L, labrum.

\section{Location of the Tear}

Labral tears occur commonly in the anterosuperior aspect of the acetabulum; however, there are exceptions to this rule, and labral tears can be found outside this region. An accurate description of the location of the tear according to a widely used clock-face analogy ${ }^{128}$ helps with planned arthroscopic portal placement to allow for more difficult suture anchor deployment locations and suture passing techniques. Furthermore, the location of the tear itself can be a result of an underlying pathology. Examples of such are psoas impingement and subspine impingement as seen in a 3 o'clock tear and a 12 o'clock tear, respectively. These can then be managed simultaneously with either psoas tendon lengthening for psoas impingement or subspine decompression for subspine impingement, alongside the associated labral repair.

\section{Size of the Labrum}

Labral size is becoming an area of interest to hip surgeons. The ability to identify preoperatively a hypertrophic and hypoplastic labrum can enhance the preoperative plan. The hypertrophic labrum may be an adaptive response of the hip to undercoverage such as dysplasia, and its identification before embarking on hip surgery is paramount. ${ }^{129-131}$ The identification of a hypertrophic labrum may delineate the need for adjunct procedures, such as a periacetabular osteotomy, in the setting of hip dysplasia. Furthermore, a hypertrophic labrum can provide a technical challenge in atraumatic access to the joint because it may obscure arthroscopic portal placement. Thus identifying the labral size before intervention can enhance the surgeon's ability to plan for potential challenges as well as repair strategies. Conversely, a preoperative awareness of a hypoplastic labrum is of equal importance. A labrum $<3$ mm thick may not be repairable with the current instrumentation and techniques available. ${ }^{127}$ Therefore, hip surgeons may plan for primary labral augmentation or reconstruction with a graft in this setting. Having knowledge of a hypoplastic labrum allows for preparation for all potential interventions.

\section{Cartilage}

The cartilage layer is an important predictor of the successful management of FAI. Cartilage injuries can present as chondromalacia (roughening of surface, fibrillations), chondral debonding (loss of fixation to the subchondral bone but macroscopically intact, wave sign), cleavage (loss of fixation 
to subchondral bone frayed edges, or a flap), and a fullthickness defect. ${ }^{6}$

The long-term outcomes of hip-preserving surgery may be determined by the condition of the cartilage as seen on a preoperative imaging work-up. ${ }^{132,133}$

Detailed knowledge of the MRI-based condition of the cartilage provides some important advantages. First, the surgeon can educate the patient appropriately regarding anticipated outcomes and realistic expectations. Second, identifying the characteristics of a cartilage defect before surgery allows the surgeon to plan for the appropriate equipment availability. Finally, preoperative knowledge of the condition of the cartilage helps refine surgical indications and allows for definitive surgical recommendations.

\section{Size of Lesion}

Details on the size of the cartilage lesion can facilitate the operative management. On one side of the spectrum, cartilage damage $>60$ degrees of the acetabular circumference was associated with the failure end point of conversion to THA. $^{28}$ Therefore surgical intervention can proceed with caution in these cases. However, smaller sized lesions are amenable to other interventions such as microfracture, fibrin adhesive, autologous chondrocyte implantation, and autologous membrane-induced chondrogenesis. ${ }^{134-136}$ Therefore the amount of cartilage loss identified preoperatively on MRI, especially if quantified, may help determine the best approach.

\section{Location of Lesion}

Acetabular cartilage lesions are most common, and their association with acetabular cystic changes is important to identify preoperatively because there is a spatial relationship between labral pathology and cartilage injury. Although most cartilage lesions are acetabular sided, femoral head lesions do occur and may require treatment as well. The 70degree arthroscope can assess $80 \%$ of the femoral head cartilage surface, and therefore location of the cartilage defect as determined by preoperative MRI is critical. Likewise, if the cartilage lesion is in a non-weightbearing zone of the hip, operative management may not be indicated. The surgical approach chosen (open or arthroscopic) will be influenced by an accurate report of the lesion location.

\section{High-resolution Cartilage Imaging: Future Directions}

Advancement in cartilage imaging has been by way of delayed gadolinium-enhanced magnetic resonance imaging of cartilage (dGEMRIC), T1 rho, and T2 mapping. Both dGEMRIC and T1rho are sensitive to extracellular glycosaminoglycan and can detect the severity and location of cartilage damage in relation to the size and position of a cam lesion. ${ }^{137}$ T2 mapping is sensitive to water and collagen and can identify early degenerative-associated changes such as water content and collagen arrangement. ${ }^{138}$ Although not yet validated or widely available, if these biochemically sensitive cartilage-imaging techniques can predict radiographic arthritis, they will identify patients for early preventive treatment of FAI before irreversible cartilage damage.

\section{Extra-articular Impingement}

Biomechanical analysis in young patients with hip pain has proven to identify particular morphologies of hip structures that can generate symptomatic extra-articular impingement (EAI). Several types were identified according to the involved anatomical structures. The clinical significance of EAI depends on the presence of concomitant intra-articular impingement, instability, or chondrolabral injury.

\section{Subspine Impingement}

Impingement between the distal portion of AIIS and ventral femoral neck was named subspine impingement (SI). It was described by Gallagher ${ }^{139}$ in 1935 as a consequence of an avulsion fracture of the rectus femoris muscle origin. The callus formation after this fracture leads to a hypertrophic remodeling of the AIIS that can cause this pattern of impingement. Hip flexion and internal rotation in patients with SI place the labrum and cartilage under strain and compression forces that can cause damage. Hetsroni et al described camtype FAI in $90 \%$ of the patients with SI. ${ }^{140}$ Because most patients have articular pathology, it is difficult to recognize if the symptoms are related to EAI or purely to FAI. According to AIIS morphology, it can be divided into different types ${ }^{141,142}$ : type I, usually of normal morphology, with a notch or contact surface between the AIIS and the acetabular rim; type II when the AIIS extends to the level of the rim, with a flat surface (type IIa) or convex surface (type IIb); and type III when the AIIS extends distally to the acetabular rim. Hetsroni and colleagues correlated these three types with different restrictions of ROM. Type I represents normality, ${ }^{141}$ but type Ila can also be asymptomatic, according to the modification proposed by Morales-Avalos et al. To improve ROM, an AIIS resection, open or arthroscopic, is the standard treatment. The anatomical origin of the rectus femoris muscle in the AIIS is variable. All have described it as a muscle-free area of $5 \mathrm{~mm}$ inferior and medial to the spine that allows a secure decompression area, avoiding weakness of the muscle insertion, when the resection is $<10 \mathrm{~mm} .{ }^{143}$ In some cases, arthroscopic decompression results in predictable pain relief and increased hip flexion. ${ }^{112}$

\section{Femoral Torsion}

Femoral torsion, defined between the femoral neck axis and the condylar axis in the axial plane line, should range between 10 and 20 degrees. ${ }^{144}$ Antetorsion (torsion $>20$ degrees) and retrotorsion (torsion $<10$ degrees) could be related to hip pain and are associated with significant variations in ROM. It is generally accepted that antetorsion is related to hip instability and retrotorsion to impingement. The association of antetorsion and coxa valga was examined by Siebenrock et al, ${ }^{29}$ suggesting that femoral osteotomies should be performed to correct EAI, but there is no reference to soft tissue damage or the definitive surgical treatment used. Lerch and colleagues ${ }^{145}$ studied a population of 462 symptomatic patients with hip pain related to FAI or dysplasia and observed abnormalities in femoral version in $52 \%$ of cases. Severe torsional deformities were present in $17 \%$, and only $32 \%$ of all hips had normal femoral version combined 
with normal acetabular version. Those observations point clearly to the need to include an assessment of femoral version and acetabular version in the diagnostic algorithm of the nonarthritic painful hip.

\section{Trochanteric Impingement}

Impingement between the GT and pelvic bones was described and classified according to Ricciardi et al. ${ }^{146} \mathrm{He}$ proposed a classification based on the areas of impingement, suggesting a type 1 between the anterior facet of the GT and anterior acetabular rim or AIIS associated with femoral retrotorsion, a type 2 between the posterolateral area of the GT and the ischium associated with femoral antetorsion, and a type 3 presenting a complex impingement between the GT and ilium and ischium. Trochanteric impingement is very difficult to diagnose based on the current imaging techniques, and it relies more on intraoperative observations.

\section{Ischiofemoral Impingement}

First described by Johnson in 1977, ${ }^{147}$ ischiofemoral impingement (IFI) results from a pathologic narrow space between the ischium and lesser trochanter. ${ }^{144}$ Quadratus femoris muscle is the main structure compressed between the hard bone surfaces when the hip is in extension, external rotation, and adduction. Various conditions can predispose to this mechanism of EAI: coxa valga with high antetorsion, decrease in lateral offset after THA, Perthes disease, injury to the hamstrings tendons, exostosis, enchondromas, or ipsilateral gluteal insufficiency. ${ }^{144}$ Posterior hip pain is the typical clinical presentation; it can be provoked with the "long stride walking test" or the IFI test (passive extension, adduction, and external rotation). ${ }^{29}$ The distance of $15 \mathrm{~mm}$ between the lesser trochanter and the ischium seems to be the cutoff value to define a narrow space between the lesser trochanter and ischium in MRI measurement. ${ }^{146}$ To some extent this distance seems to be arbitrary because there is no predefined rotational position of the lower limb while acquiring the MRI sequences and no consensus regarding the relation of femur torsional profile with this value. At the present time, the diagnosis is mainly based on a clinical observation of the patient with limited painful hip external rotation, adduction, and extension. Some recent simulation software may allow a more accurate diagnosis of this condition using anatomical 3D patient-based models. ${ }^{29}$ In the absence of predisposing conditions, the initial treatment should be conservative with anti-inflammatory medication, physiotherapy, and sonography-guided injections. In persistent symptomatic patients, a resection ${ }^{148}$ or advancement ${ }^{149}$ of the lesser trochanter might be performed. In the presence of predisposing malalignment deformities, proximal femur osteotomies might be necessary to improve hip stability and restore physiologic ROM.

Diagnosis of EAI is challenging because intra-articular pathology is usually present. ${ }^{140}$ Different classification systems have been proposed, but the risk of articular damage is not well established. The pathophysiology of EAI can be related to articular damage, limitation in normal ROM, extra-articular soft tissue damage, or a combination of them all. Articular damage can be due to either impingement or instability, and it is important to establish a proper diagnosis to perform adequate therapeutic planification (-Table 4).

\section{Conclusions}

Hip mechanical disorders present a wide variation of altered morphological and functional parameters, many times not easy to assess. The spectrum of disorders goes from severe instability, as seen on acetabular dysplasia, to severe impingement, as seen in protrusio hips. Between the two extremes, a variety of isolated or combined morphologies can produce severe symptoms and limit function.

Simple radiographs in AP and lateral profile views should be the mainstay for imaging diagnostic algorithms. Acetabular depth and spatial orientation, femoral head coverage, femoral torsional profile, and head-neck waist morphology are important parameters that, combined with detailed physical examination, should offer solid indications for understanding the cause of symptoms. MRI is necessary to identify cartilage and labrum lesions and, in mixed morphologies, to identify indirect signs of less obvious instability or subtle impingement. MRI should never be used before conventional radiographs or as the only diagnostic modality. If so, parameters related to bone morphology like acetabular coverage and version should never be reported without a complementary radiographic analysis.

Surgical techniques for hip preservation have become sophisticated as a consequence of the detailed knowledge of hip anatomy and vascular supply. Radiologists should keep up with this evolution to provide the proper tools to help surgeons select the most rational approach for a complex problem.

\section{Conflict of Interest}

Olufemi R. Ayeni participates in the Conmed speaker's bureau. Paul E. Beaulé receives grants from Zimmer Biomet and personal fees from Zimmer Biomet, Medacta, CORIN, and MicroPORT outside the submitted work. Pedro Dantas reports personal fees from Smith \& Nephew outside the submitted work. The remaining authors have declared no conflicts of interest for this article.

\section{Acknowledgments}

We wish to thank Dr. Vasco Mascarenhas, guest editor of this issue of Seminars in Musculoskeletal Radiology, for the kind invitation to write this article.

\section{References}

1 Smith-Petersen MN. The classic: Treatment of malum coxae senilis, old slipped upper femoral epiphysis, intrapelvic protrusion of the acetabulum, and coxa plana by means of acetabuloplasty. 1936. Clin Orthop Relat Res 2009;467(03):608-615

2 Ito K, Minka MA II, Leunig M, Werlen S, Ganz R. Femoroacetabular impingement and the cam-effect. A MRI-based quantitative anatomical study of the femoral head-neck offset. J Bone Joint Surg Br 2001;83(02):171-176 
3 Ganz R, Parvizi J, Beck M, Leunig M, Nötzli H, Siebenrock KA. Femoroacetabular impingement: a cause for osteoarthritis of the hip. Clin Orthop Relat Res 2003;(417):112-120

4 Ganz R, Gill TJ, Gautier E, Ganz K, Krügel N, Berlemann U. Surgical dislocation of the adult hip a technique with full access to the femoral head and acetabulum without the risk of avascular necrosis. J Bone Joint Surg Br 2001;83(08):1119-1124

5 Siebenrock KA, Wahab KHA, Werlen S, Kalhor M, Leunig M, Ganz R. Abnormal extension of the femoral head epiphysis as a cause of cam impingement. Clin Orthop Relat Res 2004;(418):54-60

6 Beck M, Kalhor M, Leunig M, Ganz R. Hip morphology influences the pattern of damage to the acetabular cartilage: femoroacetabular impingement as a cause of early osteoarthritis of the hip. J Bone Joint Surg Br 2005;87(07):1012-1018

7 Ganz R, Leunig M, Leunig-Ganz K, Harris WH. The etiology of osteoarthritis of the hip: an integrated mechanical concept. Clin Orthop Relat Res 2008;466(02):264-272

8 Corten K, Ganz R, Chosa E, Leunig M. Bone apposition of the acetabular rim in deep hips: a distinct finding of global pincer impingement. J Bone Joint Surg Am 2011;93(Suppl 2):10-16

9 Kraeutler MJ, Chadayammuri V, Garabekyan T, Mei-Dan O. Femoral version abnormalities significantly outweigh effect of cam impingement on hip internal rotation. J Bone Joint Surg Am 2018;100(03):205-210

10 Murray RO. The aetiology of primary osteoarthritis of the hip. Br J Radiol 1965;38(455):810-824

11 Buckwalter JA, Anderson DD, Brown TD, Tochigi Y, Martin JA. The roles of mechanical stresses in the pathogenesis of osteoarthritis: implications for treatment of joint injuries. Cartilage 2013;4 (04):286-294

12 Ganz R, Horowitz K, Leunig M. Algorithm for femoral and periacetabular osteotomies in complex hip deformities. Clin Orthop Relat Res 2010;468(12):3168-3180

13 Leunig M, Puloski S, Beck M, Siebenrock K-A, Ganz R. Proximal femoral osteotomy: current indications and techniques. Semin Arthroplasty 2005;16:53-62

14 Tannast M, Macintyre N, Steppacher SD, Hosalkar HS, Ganz R, Siebenrock KA. A systematic approach to analyze the sequelae of LCPD. Hip Int 2013;23(Suppl 9):S61-S70

15 Bogunovic L, Gottlieb M, Pashos G, Baca G, Clohisy JC. Why do hip arthroscopy procedures fail? Clin Orthop Relat Res 2013;471 (08):2523-2529

16 Ross JR, Larson CM, Adeoye O, Kelly BT, Bedi A. Residual deformity is the most common reason for revision hip arthroscopy: a three-dimensional CT study. Clin Orthop Relat Res 2015;473 (04):1388-1395

17 Rego PR, Mascarenhas V, Oliveira FS, et al. Morphologic and angular planning for cam resection in femoro-acetabular impingement: value of the omega angle. Int Orthop 2016;40(10): 2011-2017

18 Rego P, Mascarenhas V, Collado D, Coelho A, Barbosa L, Ganz R. Arterial topographic anatomy near the femoral head-neck perforation with surgical relevance. J Bone Joint Surg Am 2017;99 (14):1213-1221

19 Marin-Peña O, Tey-Pons M, Perez-Carro L, et al. The current situation in hip arthroscopy. EFORT Open Rev 2017;2(03):58-65

20 Montgomery SR, Ngo SS, Hobson T, et al. Trends and demographics in hip arthroscopy in the United States. Arthroscopy 2013;29(04):661-665

21 Peters S, Laing A, Emerson C, et al. Surgical criteria for femoroacetabular impingement syndrome: a scoping review. Br J Sports Med 2017;51(22):1605-1610

22 Nwachukwu BU, Rebolledo BJ, McCormick F, Rosas S, Harris JD, Kelly BT. Arthroscopic versus open treatment of femoroacetabular impingement: a systematic review of medium- to long-term outcomes. Am J Sports Med 2016;44(04):1062-1068

23 Rego PA, Mascarenhas V, Oliveira FS, Pinto PC, Sampaio E, Monteiro J. Arthroscopic versus open treatment of cam-type femoro-acetabular impingement: retrospective cohort clinical study. Int Orthop 2018;42(04):791-797

24 Nepple JJ, Clohisy JC; ANCHOR Study Group Members. Evolution of femoroacetabular impingement treatment: the ANCHOR experience. Am J Orthop 2017;46(01):28-34

25 Zaltz I, Kelly BT, Larson CM, Leunig M, Bedi A. Surgical treatment of femoroacetabular impingement: what are the limits of hip arthroscopy? Arthroscopy 2014;30(01):99-110

26 Costa Rocha P, Klingenstein G, Ganz R, Kelly BT, Leunig M. Circumferential reconstruction of severe acetabular labral damage using hamstring allograft: surgical technique and case series. Hip Int 2013;23(Suppl 9):S42-S53

27 Audenaert EA, Peeters I, Vigneron L, Baelde N, Pattyn C. Hip morphological characteristics and range of internal rotation in femoroacetabular impingement. Am J Sports Med 2012;40(06): 1329-1336

28 Tannast M, Siebenrock KA, Anderson SE. Femoroacetabular impingement: radiographic diagnosis-what the radiologist should know. AJR Am J Roentgenol 2007;188(06):1540-1552

29 Siebenrock KA, Steppacher SD, Haefeli PC, Schwab JM, Tannast M. Valgus hip with high antetorsion causes pain through posterior extraarticular FAI. Clin Orthop Relat Res 2013;471(12): 3774-3780

30 Vallon F, Reymond A, Fürnstahl P, et al. Effect of angular deformities of the proximal femur on impingement-free hip range of motion in a three-dimensional rigid body model. Hip Int 2015;25 (06):574-580

31 Larson CM, Clohisy JC, Beaulé PE, et al; ANCHOR Study Group. Intraoperative and early postoperative complications after hip arthroscopic surgery: a prospective multicenter trial utilizing a validated grading scheme. Am J Sports Med 2016;44(09): 2292-2298

32 Robertson WJ, Kelly BT. The safe zone for hip arthroscopy: a cadaveric assessment of central, peripheral, and lateral compartment portal placement. Arthroscopy 2008;24(09):1019-1026

33 Bedi A, Zaltz I, De La Torre K, Kelly BT. Radiographic comparison of surgical hip dislocation and hip arthroscopy for treatment of cam deformity in femoroacetabular impingement. Am J Sports Med 2011;39(Suppl):20S-28S

34 Philippon MJ, Stubbs AJ, Schenker ML, Maxwell RB, Ganz R, Leunig M. Arthroscopic management of femoroacetabular impingement: osteoplasty technique and literature review. Am J Sports Med 2007;35(09):1571-1580

35 Horisberger M, Brunner A, Herzog RF. Arthroscopic treatment of femoroacetabular impingement of the hip: a new technique to access the joint. Clin Orthop Relat Res 2010;468(01):182-190

36 Suslak AG, Mather RC III, Kelly BT, Nho SJ. Improved arthroscopic visualization of peripheral compartment. Arthrosc Tech 2012;1 (01):e57-e62

37 Nasser R, Domb B. Hip arthroscopy for femoroacetabular impingement. EFORT Open Rev 2018;3(04):121-129

38 Matsuda DK. Acute iatrogenic dislocation following hip impingement arthroscopic surgery. Arthroscopy 2009;25(04):400-404

39 Ranawat AS, McClincy M, Sekiya JK. Anterior dislocation of the hip after arthroscopy in a patient with capsular laxity of the hip. A case report. J Bone Joint Surg Am 2009;91(01):192-197

40 Rosenbaum A, Roberts T, Flaherty M, Phillips N, Patel N, Das P. Posterior dislocation of the hip following arthroscopy-a case report and discussion. Bull Hosp Jt Dis (2013) 2014;72(02):181-184

41 Wylie JD, Beckmann JT, Maak TG, Aoki SK. Arthroscopic capsular repair for symptomatic hip instability after previous hip arthroscopic surgery. Am J Sports Med 2016;44(01):39-45

42 Harris JD, Slikker W III, Gupta AK, McCormick FM, Nho SJ. Routine complete capsular closure during hip arthroscopy. Arthrosc Tech 2013;2(02):e89-e94

43 Wuerz TH, Song SH, Grzybowski JS, et al. Capsulotomy size affects hip joint kinematic stability. Arthroscopy 2016;32(08): $1571-1580$ 
44 Kuhns BD, Weber AE, Levy DM, et al. Capsular management in hip arthroscopy: an anatomic, biomechanical, and technical review. Front Surg 2016;3:13

45 Larson CM, Giveans MR. Arthroscopic debridement versus refixation of the acetabular labrum associated with femoroacetabular impingement. Arthroscopy 2009;25(04):369-376

46 Greaves LL, Gilbart MK, Yung AC, Kozlowski P, Wilson DR. Effect of acetabular labral tears, repair and resection on hip cartilage strain: A 7T MR study. J Biomech 2010;43(05):858-863

47 Olach M, Gerhard P, Giesinger K, Lampert C, Erhardt JB. Clinical and radiological outcome at mean follow-up of 11 years after hip arthroscopy. Arch Orthop Trauma Surg 2019;139(01):1-6

48 Degen RM, Poultsides L, Mayer SW, et al. Safety of hip anchor insertion from the midanterior and distal anterolateral portals with a straight drill guide: a cadaveric study. Am J Sports Med 2017;45(03):627-635

49 Liechti EF, Ferguson SJ, Tannast M. Protrusio acetabuli: joint loading with severe pincer impingement and its theoretical implications for surgical therapy. J Orthop Res 2015;33(01):106-113

50 Hanke MS, Steppacher SD, Zurmühle CA, Siebenrock KA, Tannast M. Hips with protrusio acetabuli are at increased risk for failure after femoroacetabular impingement surgery: a 10-year followup. Clin Orthop Relat Res 2016

51 Chandrasekaran S, Darwish N, Martin TJ, Suarez-Ahedo C, Lodhia P, Domb BG. Arthroscopic capsular plication and labral seal restoration in borderline hip dysplasia: 2-year clinical outcomes in 55 cases. Arthroscopy 2017;33(07):1332-1340

52 Wyatt MC, Beck M. The management of the painful borderline dysplastic hip. J Hip Preserv Surg 2018;5(02):105-112

53 Wijdicks CA, Balldin BC, Jansson KS, Stull JD, LaPrade RF, Philippon MJ. Cam lesion femoral osteoplasty: in vitro biomechanical evaluation of iatrogenic femoral cortical notching and risk of neck fracture. Arthroscopy 2013;29(10):1608-1614

54 Ganz R, Gill TJ, Gautier E, Ganz K, Krügel N, Berlemann U. Surgical dislocation of the adult hip a technique with full access to the femoral head and acetabulum without the risk of avascular necrosis. J Bone Joint Surg Br 2001;83(08):1119-1124

55 Schoeniger R, LaFrance AE, Oxland TR, Ganz R, Leunig M. Does trochanteric step osteotomy provide greater stability than classic slide osteotomy? A preliminary study. Clin Orthop Relat Res 2009;467(03):775-782

56 Bastian JD, Wolf AT, Wyss TF, Nötzli HP. Stepped osteotomy of the trochanter for stable, anatomic refixation. Clin Orthop Relat Res 2009;467(03):732-738

57 Kalhor M, Beck M, Huff TW, Ganz R. Capsular and pericapsular contributions to acetabular and femoral head perfusion. J Bone Joint Surg Am 2009;91(02):409-418

58 Kalhor M, Horowitz K, Gharehdaghi J, Beck M, Ganz R. Anatomic variations in femoral head circulation. Hip Int 2012;22(03): 307-312

59 Kamath AF, Ganz R, Zhang H, Grappiolo G, Leunig M. Subtrochanteric osteotomy for femoral mal-torsion through a surgical dislocation approach. J Hip Preserv Surg 2015;2(01):65-79

60 Weidner J, Wyatt M, Beck M. Labral augmentation with ligamentum capitis femoris: presentation of a new technique and preliminary results. J Hip Preserv Surg 2018;5(01):47-53

61 Steppacher SD, Anwander H, Zurmühle CA, Tannast M, Siebenrock KA. Eighty percent of patients with surgical hip dislocation for femoroacetabular impingement have a good clinical result without osteoarthritis progression at 10 years. Clin Orthop Relat Res 2015;473(04):1333-1341

62 Menge TJ, Briggs KK, Dornan GJ, McNamara SC, Philippon MJ. Survivorship and outcomes 10 years following hip arthroscopy for femoroacetabular impingement: labral debridement compared with labral repair. J Bone Joint Surg Am 2017;99(12):997-1004

63 Palmer DH, Ganesh V, Comfort T, Tatman P. Midterm outcomes in patients with cam femoroacetabular impingement treated arthroscopically. Arthroscopy 2012;28(11):1671-1681
64 Reiman MP, Peters S, Sylvain J, Hagymasi S, Ayeni OR. Prevalence and consistency in surgical outcome reporting for femoroacetabular impingement syndrome: a scoping review. Arthroscopy 2018;34(04):1319-1328.e9

65 Mannion AF, Impellizzeri FM, Naal FD, Leunig M. Fulfilment of patient-rated expectations predicts the outcome of surgery for femoroacetabular impingement. Osteoarthritis Cartilage 2013; 21(01):44-50

66 Cicuttini FM, Teichtahl AJ, Wang Y. Hip arthroscopy for femoroacetabular impingement: use escalating beyond the evidence. Med J Aust 2017;206(10):424-426

67 Beaulé PE, Bleeker H, Singh A, Dobransky J. Defining modes of failure after joint-preserving surgery of the hip. Bone Joint $\mathrm{J}$ 2017;99-B(03):303-309

68 Chegini S, Beck M, Ferguson SJ. The effects of impingement and dysplasia on stress distributions in the hip joint during sitting and walking: a finite element analysis. J Orthop Res 2009;27(02): 195-201

69 Hellwig FL, Tong J, Hussell JG. Hip joint degeneration due to cam impingement: a finite element analysis. Comput Methods Biomech Biomed Engin 2016;19(01):41-48

$70 \mathrm{Ng}$ KCG, Rouhi G, Lamontagne M, Beaulé PE. Finite element analysis examining the effects of cam FAI on hip joint mechanical loading using subject-specific geometries during standing and maximum squat. HSS J 2012;8(03):206-212

71 Jorge JP, Simões FM, Pires EB, et al. Finite element simulations of a hip joint with femoroacetabular impingement. Comput Methods Biomech Biomed Engin 2014;17(11):1275-1284

72 Lourenço J, Simões FMF, Rego PA. Finite element analyses of femoroacetabular impingement before and after hip arthroscopy. Biomed Mater Eng 2015;26(3-4):193-206

73 Ferguson SJ. Biomechanics of the Acetabular Labrum [dissertation]. Kingston, Canada: Queen's University; 2001

74 Petersen W, Petersen F, Tillmann B. Structure and vascularization of the acetabular labrum with regard to the pathogenesis and healing of labral lesions. Arch Orthop Trauma Surg 2003;123 (06):283-288

75 Fernquest S, Arnold C, Palmer A, et al. Osseous impingement occurs early in flexion in cam-type femoroacetabular impingement: a 4D CT model. Bone Joint J 2017;99-B(4, Suppl B):41-48

76 Meyer DC, Beck M, Ellis T, Ganz R, Leunig M. Comparison of six radiographic projections to assess femoral head/neck asphericity. Clin Orthop Relat Res 2006;445(445):181-185

77 Rippstein J. Determination of the antetorsion of the femur neck by means of two x-ray pictures [in German]. Z Orthop Ihre Grenzgeb 1955;86(03):345-360

78 Locher S, Werlen S, Leunig M, Ganz R. Arthro-MRI mit radiärer Schnittsequenz zur Darstellung der präradiologischen Hüftpathologie. Z Orthop Ihre Grenzgeb 2002;140(01):52-57

79 Nötzli HP, Wyss TF, Stoecklin CH, Schmid MR, Treiber K, Hodler J. The contour of the femoral head-neck junction as a predictor for the risk of anterior impingement.J Bone Joint Surg Br 2002;84(04):556-560

80 Martin RK, Dzaja I, Kay J, et al. Radiographic outcomes following femoroacetabular impingement correction with open surgical management: a systematic review. Curr Rev Musculoskelet Med 2016;9(04):402-410

81 Rakhra KS, Sheikh AM, Allen D, Beaulé PE. Comparison of MRI alpha angle measurement planes in femoroacetabular impingement. Clin Orthop Relat Res 2009;467(03):660-665

82 Bouma HW, Hogervorst T, Audenaert E, Krekel P, van Kampen PM. Can combining femoral and acetabular morphology parameters improve the characterization of femoroacetabular impingement? Clin Orthop Relat Res 2015;473(04):1396-1403

83 Mascarenhas VV, Rego P, Dantas P, Gaspar A, Soldado F, Consciência JG. Cam deformity and the omega angle, a novel quantitative measurement of femoral head-neck morphology: a 3D CT gender analysis in asymptomatic subjects. Eur Radiol 2017;27(05):2011-2023 
84 Cross MB, Fabricant PD, Maak TG, Kelly BT. Impingement (acetabular side). Clin Sports Med 2011;30(02):379-390

85 Philippon MJ, Schenker ML. Arthroscopy for the treatment of femoroacetabular impingement in the athlete. Clin Sports Med 2006;25(02):299-308, ix

86 Larson CM, Giveans MR, Stone RM. Arthroscopic debridement versus refixation of the acetabular labrum associated with femoroacetabular impingement: mean 3.5-year follow-up. Am J Sports Med 2012;40(05):1015-1021

87 Ferguson SJ, Bryant JT, Ganz R, Ito K. An in vitro investigation of the acetabular labral seal in hip joint mechanics. J Biomech 2003; 36(02):171-178

88 Siebenrock KA, Kistler L, Schwab JM, Büchler L, Tannast M. The acetabular wall index for assessing anteroposterior femoral head coverage in symptomatic patients. Clin Orthop Relat Res 2012; 470(12):3355-3360

89 Kalberer F, Sierra RJ, Madan SS, Ganz R, Leunig M. Ischial spine projection into the pelvis : a new sign for acetabular retroversion. Clin Orthop Relat Res 2008;466(03):677-683

90 Reynolds D, Lucas J, Klaue K. Retroversion of the acetabulum. A cause of hip pain. J Bone Joint Surg Br 1999;81(02):281-288

91 Kelly B, Philippon MJ, eds. Arthroscopic Techniques of the Hip. Thorofare, NJ: Slack Inc; 2009

92 Tannast M, Pfannebecker P, Schwab JM, Albers CE, Siebenrock KA, Büchler L. Pelvic morphology differs in rotation and obliquity between developmental dysplasia of the hip and retroversion. Clin Orthop Relat Res 2012;470(12):3297-3305

93 Zaltz I, Kelly BT, Hetsroni I, Bedi A. The crossover sign overestimates acetabular retroversion. Clin Orthop Relat Res 2013; 471(08):2463-2470

94 Leunig M. CORR Insights ${ }^{\mathrm{TM}}$ : Femoroacetabular impingement predisposes to traumatic posterior hip dislocation. Clin Orthop Relat Res 2013;471(06):1944-1945

95 Steppacher SD, Albers CE, Siebenrock KA, Tannast M, Ganz R. Femoroacetabular impingement predisposes to traumatic posterior hip dislocation. Clin Orthop Relat Res 2013;471(06):1937-1943

96 Zurmühle CA, Anwander H, Albers CE, et al. Periacetabular osteotomy provides higher survivorship than rim trimming for acetabular retroversion. Clin Orthop Relat Res 2017;475(04): $1138-1150$

97 Siebenrock KA, Kalbermatten DF, Ganz R. Effect of pelvic tilt on acetabular retroversion: a study of pelves from cadavers. Clin Orthop Relat Res 2003;(407):241-248

98 Tannast M, Zheng G, Anderegg C, et al. Tilt and rotation correction of acetabular version on pelvic radiographs. Clin Orthop Relat Res 2005;438(438):182-190

99 Leunig M, Nho SJ, Turchetto L, Ganz R. Protrusio acetabuli: new insights and experience with joint preservation. Clin Orthop Relat Res 2009;467(09):2241-2250

100 Anderson LA, Anderson MB, Erickson JA, Chrastil J, Peters CL. Acetabular wall indices help to distinguish acetabular coverage in asymptomatic adults with varying morphologies. Clin Orthop Relat Res 2017;475(04):1027-1033

101 Anderson LA, Kapron AL, Aoki SK, Peters CL. Coxa profunda: is the deep acetabulum overcovered? Clin Orthop Relat Res 2012; 470(12):3375-3382

102 Nepple JJ, Lehmann CL, Ross JR, Schoenecker PL, Clohisy JC. Coxa profunda is not a useful radiographic parameter for diagnosing pincer-type femoroacetabular impingement. J Bone Joint Surg Am 2013;95(05):417-423

103 Beaulé PE, Byrd T, Wilkin G, et al. Nonarthroplasty Joint-Preserving Surgery for Hip Disorders. Orthopaedic Knowledge Update: Hip and Knee Reconstruction 5. Philadelphia, PA: Lippincott Williams \& Wilkins; 2016

104 McKibbin B. Anatomical factors in the stability of the hip joint in the newborn. J Bone Joint Surg Br 1970;52(01):148-159

105 Menschik F. The hip joint as a conchoid shape. J Biomech 1997;30 (09):971-973
106 Bullough P, Goodfellow J, O'Conner J. The relationship between degenerative changes and load-bearing in the human hip. J Bone Joint Surg Br 1973;55(04):746-758

107 Grammatopoulos G, Speirs AD, Ng KCG, et al. Acetabular and spino-pelvic morphologies are different in subjects with symptomatic cam femoro-acetabular impingement. J Orthop Res 2018;36(07):1840-1848

108 Gilles B, Christophe FK, Magnenat-Thalmann N, et al. MRI-based assessment of hip joint translations. J Biomech 2009;42(09): 1201-1205

109 Beaulé PE, Grammatopoulos G, Speirs A, et al. Unravelling the hip pistol grip/cam deformity: origins to joint degeneration. J Orthop Res 2018;36(12):3125-3135

110 Speirs AD, Beaulé PE, Rakhra KS, Schweitzer ME, Frei H. Bone density is higher in cam-type femoroacetabular impingement deformities compared to normal subchondral bone. Osteoarthritis Cartilage 2013;21(08):1068-1073

111 Nepple JJ, Prather H, Trousdale RT, et al. Clinical diagnosis of femoroacetabular impingement. J Am Acad Orthop Surg 2013;21 (Suppl 1):S16-S19

112 Larson CM, Kelly BT, Stone RM. Making a case for anterior inferior iliac spine/subspine hip impingement: three representative case reports and proposed concept. Arthroscopy 2011;27(12): 1732-1737

113 Ng KCG, Lamontagne M, Jeffers JRT, Grammatopoulos G, Beaulé PE. Anatomic predictors of sagittal hip and pelvic motions in patients with a cam deformity. Am J Sports Med 2018;46(06): 1331-1342

114 Mascarenhas VV, Rego P, Dantas P, et al. Can we discriminate symptomatic hip patients from asymptomatic volunteers based on anatomic predictors? A 3-dimensional magnetic resonance study on cam, pincer, and spinopelvic parameters. Am J Sports Med 2018;46(13):3097-3110

115 Jamali AA, Mladenov K, Meyer DC, et al. Anteroposterior pelvic radiographs to assess acetabular retroversion: high validity of the "cross-over-sign.". J Orthop Res 2007;25(06):758-765

116 Dandachli W, Islam SU, Liu M, Richards R, Hall-Craggs M, Witt J. Three-dimensional CT analysis to determine acetabular retroversion and the implications for the management of femoroacetabular impingement. J Bone Joint Surg Br 2009;91(08): 1031-1036

117 Tönnis D, Storch K, Ulbrich H. Results of newborn screening for CDH with and without sonography and correlation of risk factors. J Pediatr Orthop 1990;10(02):145-152

118 Cooperman DR, Wallensten R, Stulberg SD. Acetabular dysplasia in the adult. Clin Orthop Relat Res 1983;(175):79-85

119 Pitto RP, Klaue K, Ganz R, Ceppatelli S. Acetabular rim pathology secondary to congenital hip dysplasia in the adult. A radiographic study. Chir Organi Mov 1995;80(04):361-368

120 Tönnis D, Heinecke A. Acetabular and femoral anteversion: relationship with osteoarthritis of the hip. J Bone Joint Surg Am 1999;81(12):1747-1770

121 Dandachli W, Kannan V, Richards R, Shah Z, Hall-Craggs M, Witt $\mathrm{J}$. Analysis of cover of the femoral head in normal and dysplastic hips: new CT-based technique. J Bone Joint Surg Br 2008;90(11): 1428-1434

122 Jacobsen S, Rømer L, Søballe K. The other hip in unilateral hip dysplasia. Clin Orthop Relat Res 2006;446(446):239-246

123 Wilkin GP, Ibrahim MM, Smit KM, Beaulé PE. A contemporary definition of hip dysplasia and structural instability: toward a comprehensive classification for acetabular dysplasia. J Arthroplasty 2017;32(9S):S20-S27

124 Seldes RM, Tan V, Hunt J, Katz M, Winiarsky R, Fitzgerald RH Jr. Anatomy, histologic features, and vascularity of the adult acetabular labrum. Clin Orthop Relat Res 2001;(382):232-240

125 Safran MR. The acetabular labrum: anatomic and functional characteristics and rationale for surgical intervention. J Am Acad Orthop Surg 2010;18(06):338-345 
126 Song Y, Ito H, Kourtis L, Safran MR, Carter DR, Giori NJ. Articular cartilage friction increases in hip joints after the removal of acetabular labrum. J Biomech 2012;45(03):524-530

127 Herickhoff PK, Safran MR. Surgical decision making for acetabular labral tears: an international perspective. Orthop J Sports Med 2018;6(09):2325967118797324

128 Philippon MJ, Michalski MP, Campbell KJ, et al. An anatomical study of the acetabulum with clinical applications to hip arthroscopy. J Bone Joint Surg Am 2014;96(20):1673-1682

129 Garabekyan T, Ashwell Z, Chadayammuri V, et al. Lateral acetabular coverage predicts the size of the hip labrum. Am J Sports Med 2016;44(06):1582-1589

130 Petersen BD, Wolf B, Lambert JR, et al. Lateral acetabular labral length is inversely related to acetabular coverage as measured by lateral center edge angle of Wiberg. J Hip Preserv Surg 2016;3 (03):190-196

131 James S, Miocevic M, Malara F, Pike J, Young D, Connell D. MR imaging findings of acetabular dysplasia in adults. Skeletal Radiol 2006;35(06):378-384

132 Philippon MJ, Briggs KK, Yen Y-M, Kuppersmith DA. Outcomes following hip arthroscopy for femoroacetabular impingement with associated chondrolabral dysfunction: minimum two-year follow-up. J Bone Joint Surg Br 2009;91(01):16-23

133 Beck M, Leunig M, Parvizi J, Boutier V, Wyss D, Ganz R. Anterior femoroacetabular impingement: part II. Midterm results of surgical treatment. Clin Orthop Relat Res 2004;(418):67-73

134 O'Connor M, Minkara AA, Westermann RW, Rosneck J, Lynch TS. Outcomes of joint preservation procedures for cartilage injuries in the hip: a systematic review and meta-analysis. Orthop J Sports Med 2018;6(06):2325967118776944

135 MacDonald AE, Bedi A, Horner NS, et al. Indications and outcomes for microfracture as an adjunct to hip arthroscopy for treatment of chondral defects in patients with femoroacetabular impingement: a systematic review. Arthroscopy 2016;32(01):190-200.e2

136 Nakano N, Gohal C, Duong A, Ayeni OR, Khanduja V. Outcomes of cartilage repair techniques for chondral injury in the hip-a systematic review. Int Orthop 2018;42(10):2309-2322

137 Palmer A, Fernquest S, Rombach I, et al. Diagnostic and prognostic value of delayed Gadolinium Enhanced Magnetic Resonance Imaging of Cartilage (dGEMRIC) in early osteoarthritis of the hip. Osteoarthritis Cartilage 2017;25(09):1468-1477

138 Bittersohl B, Hosalkar HS, Hesper T, Tiderius CJ, Zilkens C, Krauspe R. Advanced imaging in femoroacetabular impingement: current state and future prospects. Front Surg 2015;2:34

139 Gallagher JR. Fracture of the anterior inferior spine of the ileum: sprinter's fracture. Ann Surg 1935;102(01):86-88
140 Hetsroni I, Larson CM, Dela Torre K, Zbeda RM, Magennis E, Kelly BT. Anterior inferior iliac spine deformity as an extraarticular source for hip impingement: a series of 10 patients treated with arthroscopic decompression. Arthroscopy 2012;28 (11):1644-1653

141 Hetsroni I, Poultsides L, Bedi A, Larson CM, Kelly BT. Anterior inferior iliac spine morphology correlates with hip range of motion: a classification system and dynamic model. Clin Orthop Relat Res 2013;471(08):2497-2503

142 Morales-Avalos R, Leyva-Villegas JI, Sanchez-Mejorada G, et al. A new morphological classification of the anterior inferior iliac spine. relevance in subspine hip impingement. Int J Morphol 2016;91(04):391-397

143 El-Shaar R, Stanton M, Biehl S, Giordano B. Effect of subspine decompression on rectus femoris integrity and iliopsoas excursion: a cadaveric study. Arthroscopy 2015;31(10):1903-1908

144 Chadayammuri V, Garabekyan T, Bedi A, et al. Passive hip range of motion predicts femoral torsion and acetabular version. J Bone Joint Surg Am 2016;98(02):127-134

145 Lerch TD, Todorski IAS, Steppacher SD, et al. Prevalence of femoral and acetabular version abnormalities in patients with symptomatic hip disease: a controlled study of 538 hips. Am J Sports Med 2018;46(01):122-134

146 Ricciardi BF, Fields KG, Wentzel C, Kelly BT, Sink EL. Short-term outcomes of open hip preservation surgery for symptomatic extraarticular femoroacetabular impingement. Hip Int 2017;27 (06):599-607

147 Johnson KA. Impingement of the lesser trochanter on the ischial ramus after total hip arthroplasty. Report of three cases. J Bone Joint Surg Am 1977;59(02):268-269

148 Kivlan BR, Martin RL, Sekiya JK. Response to diagnostic injection in patients with femoroacetabular impingement, labral tears, chondral lesions, and extra-articular pathology. Arthroscopy 2011;27(05):619-627

149 Ganz R, Slongo T, Turchetto L, Massè A, Whitehead D, Leunig M. The lesser trochanter as a cause of hip impingement: pathophysiology and treatment options. Hip Int 2013;23(Suppl 9): S35-S41

150 Gilligan I, Chandraphak S, Mahakkanukrauh P. Femoral neckshaft angle in humans: variation relating to climate, clothing, lifestyle, sex, age and side. J Anat 2013;223(02):133-151

151 Toogood PA, Skalak A, Cooperman DR. Proximal femoral anatomy in the normal human population. Clin Orthop Relat Res 2009;467 (04):876-885

152 Tönnis D. Normal values of the hip joint for the evaluation of X-rays in children and adults. Clin Orthop Relat Res 1976;(119):39-47 